\title{
Trichoderma reesei: A Fungal Enzyme Producer for Cellulosic Biofuels
}

\author{
Bernhard Seiboth, Christa Ivanova and Verena Seidl-Seiboth \\ Vienna University of Technology \\ Austria
}

\section{Introduction}

Enzymes are proteins that catalyse chemical reactions by lowering the activation energy needed and thus speed up the reaction itself. The advantage of enzymes is that they can be applied under mild reaction conditions and that they exhibit high substrate specificity, stereoselectivity and less side product formation than conventional chemical reactions, making biotechnological processes often more cost-effective than chemical approaches. Microorganisms, such as bacteria and fungi are widely exploited for the industrial production of numerous enzymes. Filamentous fungi (moulds) can grow on a wide range of substrates and efficiently degrade biopolymers and are thus an attractive resource for new enzymes. The decomposition of cellulosic plant biomass to glucose monomers for biofuel production is a typical example for an application that requires an enzyme-based approach in order to specifically cleave the glycosidic bonds between the glucose monomers of the cellulose chain and release single glucose molecules. The main enzymes necessary to degrade cellulosic plant material are cellulases and hemicellulases. The filamentous fungus Trichoderma reesei is today a paradigm for commercial scale production of different cellulases and hemicellulases and is well adapted to fermenter cultivations. Beside well established applications of these enzymes in pulp, paper, food, feed or textile processing industries, these plant cell wall degrading enzymes are nowadays also employed for the saccharification of cellulosic plant biomass to simple sugars for biofuel production (Bouws et al., 2008; Harman and Kubicek, 1998; Kumar et al., 2008). The cellulolytic potential of this pantropical fungus was already recognized during WWII through the deterioration of cotton fabrics of the US Army. Strain QM6a (originally named T. viride) was isolated from the cotton canvas of an army tent from Bougainville Island (Solomon Islands). After identification of the fungus as the cause for the massive destruction, it was put under quarantine in the eponymous Quartermaster collection of the US army at Natick. Strain QM6a was later recognized as an own species and named after its principal investigator in those years Elwyn T. Reese (Reese, 1976). It is an important peculiarity that this T. reesei strain QM6a is the ancestor of all enzyme producing T. reesei strains in commercial use. Later it was found, that, based on DNA-based phylogenetic markers, the asexual fungus $T$. reesei was indistinguishable from the sexually propagating fungus Hypocrea jecorina, thus indicating that they belong to the same species (Kuhls et al., 1996). More recent investigations demonstrated that even the original isolate T. reesei QM6a, which was for a long time considered to be an asexual clonal line, can be sexually crossed with $H$. jecorina 
strains when the requirement for a fungal strain with an opposite mating type is considered (Seidl et al., 2009). Thus, although initially classified as different genera, T. reesei and $H$. jecorina are manifestations of the same organism and according to the 'holomorph concept' the name of the teleomorph (sexual form) should be used for the species, but due to historical reasons the name of the anamorph (asexual form), T. reesei, was - and still is predominantly used as species name in publications and patents. The genome sequence of T. reesei QM6a was published in 2008 (Martinez et al., 2008) and currently two further annotated genome sequences of Trichoderma species i.e. the mycoparasitic and biocontrol fungi T. atroviride and T. virens (Kubicek et al., 2011) are available via the Joint Genome Institute (http:// genome.jgi-psf.org/). A number of species characteristics of $T$. reesei such as its smaller genome size in comparison to T. atroviride and T. virens or its reduced carbon utilization pattern indicate that $T$. reesei is a rather specialized species and highly adapted to a particular habitat which is, however, still not exactly known (Druzhinina et al., 2010). Beside its long history of safe use in industrial enzyme production which is also recognized by its GRAS status (Generally Recognized as Safe) by the U.S. Food and Drug Administration (FDA), T. reesei serves today as a model organism for the regulation and biochemistry of (hemi)cellulose degradation (Aro et al., 2005; Kubicek et al., 2009). For further deployment of enzymes for biofuel production active research efforts in different areas are currently ongoing including consolidated bioprocessing, engineering to improve enzymes by rational design or directed evolution, the generation of even better hyperproducing strains or the expression of enzymes already in the plant itself. Today, $T$. reesei is already the main industrial source for cellulases and hemicellulases (Merino and Cherry, 2007), but despite the fact that industrial strains produce more than $100 \mathrm{~g} / 1$ of cellulases (Cherry and Fidantsef, 2003), efforts are needed to reduce costs and maximize yield and efficiency of the produced enzyme mixtures (for recent reviews see e.g. Carroll and Somerville, 2009; Wilson, 2009) . In this chapter we will give an overview on T. reesei as a cellulase producer and focus on recent genomic and genetic advances that will aid in improving its cellulolytic enzyme mix, enzyme production and performance.

\section{The cellulose degradation machinery of $T$. reesei}

Lignocellulose is a mixture of cellulose associated with hemicellulose, lignin, pectin and other substances in minor amounts. It is the most abundant renewable biomass, produced by the photosynthesis of plants directly from $\mathrm{CO}_{2}$ and accumulates to approximately 200 billion metric tons worldwide. The complex structure of this solid and heterogeneous substrate hampers an efficient conversion to simple sugars and presents a number of technical and economic challenges in bringing cellulosic biofuels to the market. One of the major economical barriers for the production of biofuels is the intrinsic recalcitrance of lignocellulosic plant matter (Himmel et al., 2007). The $\beta$-(1,4)-linked glucose polysaccharide cellulose provides structure and rigidity to the plants and makes them more resistant to chemical, microbial or enzymatic degradation. The multiple hydroxyl groups of the glucose monomers are linked to oxygen molecules on neighbouring chains via hydrogen bonds, which results in the formation of microfibrils with high tensile strength. Many properties of cellulose depend also on its chain length or degree of polymerization. In addition to the general low accessibility of the insoluble microcrystalline cellulose fibres for enzymes, the additional presence of lignin and hemicellulose on the cellulose surface interferes with an efficient enzymatic degradation of this biopolymer by cellulases. The recalcitrance of plant 
biomass used for enzymatic cellulose degradation is usually reduced by a pretreatment step that exposes the cellulose microfibrils. The development of new pretreatment procedures for improved cellulose digestibility by reducing its crystallinity and the optimization of the pretreatment for different plant raw materials are a field of active ongoing research (Pedersen and Meyer, 2010; Wyman et al., 2005a; Wyman et al., 2005b; Zhu et al., 2010). However, even if a satisfactory accessibility of the plant biomass is achieved or even if pure cellulose is used as substrate, cellulose degradation itself is relatively slow and not very effective in comparison to e.g. starch degradation by (gluco)amylases and thus large enzyme loads are required to break down the crystalline cellulose parts to fermentable sugar monomers. This makes the enzyme mixtures a critical cost factor for commercially viable biofuel production (Merino and Cherry, 2007).

\subsection{T. reesei cellulase basics}

A number of different types of cellulases are necessary to degrade cellulose, but in recent years also different non-enzymatic proteins were found to add substantially to an efficient degradation. In contrast to some bacteria the cellulase multi-enzyme system of fungi is not assembled in large cellulosome complexes, but the different fungal enzymes activities are produced independently and their concerted attack on the crystalline cellulose results in a synergistic decomposition of the polymer. The cellulolytic system of $T$. reesei can be divided into three major enzyme classes: (i) exoglucanases - in the case of T. reesei cellobiohydrolases $(\mathrm{CBHs})$ - liberate the D-glucose dimer cellobiose consecutively from the ends of the cellulose chain (ii) endoglucanases (EGs) randomly cut within the cellulose chain and (iii) $\beta$ glucosidases release D-glucose from the soluble oligomeric breakdown products, thereby preventing cellobiose inhibition of the other enzymes (Fig. 1). The whole process occurs simultaneously and the rate limiting step is the depolymerisation of the insoluble cellulose by the CBHs and EGs. Both types of enzymes show considerable synergism in their simultaneous action on crystalline cellulose substrates, which is explained by the endo/exo model for synergistic degradation of cellulose (Beguin and Aubert, 1994; Tomme et al., 1995). In this model EGs hydrolyze internal cellulose bonds randomly, preferentially in the more accessible amorphous regions, thereby creating new free cellulose ends which are then the starting points for $\mathrm{CBHs}$ to further degrade the polymer starting from these amorphous regions into the crystalline regions of the cellulose. T. reesei, has two CBHs, CEL6A and CEL7A, which both are composed of two structurally and functionally distinct domains, i.e. a catalytic domain and a cellulose binding domain that are linked via a flexible linker. Some but not all of the EGs have also a two domain structure. The cellulose binding domain belongs to the carbohydrate binding modules (CBMs) and is linked either to the N-Terminus or the the C-terminus. It enables efficient attachment of the enzyme to the insoluble substrate and processive cleavage of the cellulose. After successful hydrolytic cleavage of the carbohydrate chain the enzyme does not dissociate from the substrate but stays attached and slides along the chain for the next cleavage to occur. Both CBHs, CEL6A and CEL7A, have been shown to act processively, whereby CEL6A cleaves the cellobiose dimers from the non-reducing end of the cellulose chain and CEL7A from the reducing end (Barr et al., 1996). Classification of the cellulases into exo- and endoglucanases is only a coarse model. It has been shown that some CBHs can also make internal cuts and processive EGs have also been described that produce cellotetraose instead of cellobiose.

In analogy to other enzymes that act on carbohydrate polymers, cellulases have a long substrate-binding groove running along one side of the protein that binds several consecutive 
sugar residues, generally at least two D-glucose units on each side of the catalytic center. The groove is lined by hydrogen-bonding residues, and in addition aromatic amino acid side chains are often found as hydrophobic platforms that form discrete sugar-binding subsites. EGs generally have an open binding cleft, whereas CBHs have extended loops that surround the cellulose chain so that a substrate-binding tunnel is formed. The first three-dimensional Xray structure of a cellulase was the catalytic domain of CEL6A (Rouvinen et al., 1990) followed later by CEL7A (Divne et al., 1994). Crystallization of these cellulases for structural analysis was only possible after cleavage of the CBM from the catalytic domain probably due to high flexibility of the linker region. Analysis of the CBMs reveal a wedge shaped structure with one face hydrophilic and the other more hydrophobic. In the CBM of CEL6A three tyrosines form a regular flat surface and are implicated in cellulose binding.

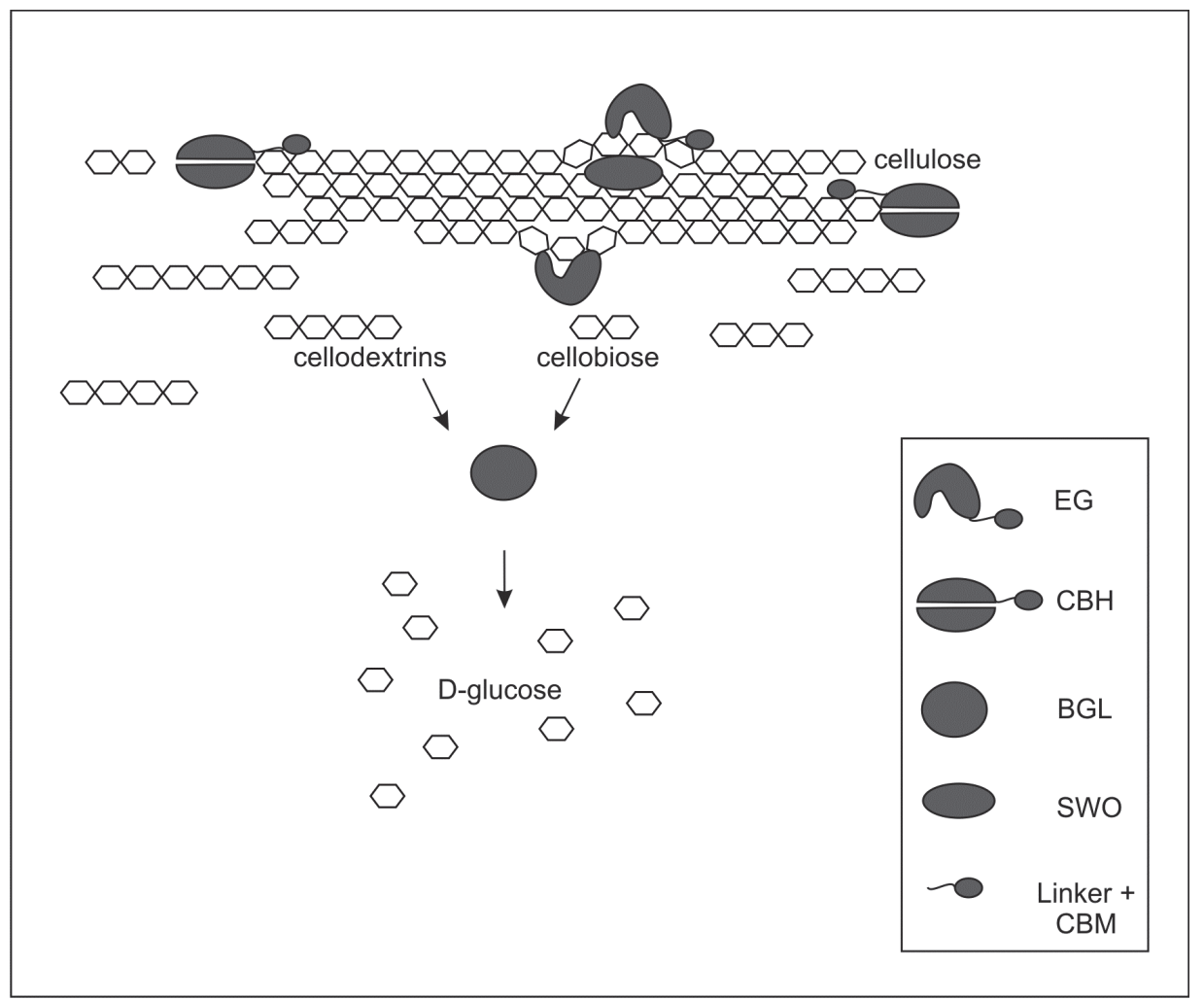

Fig. 1. Degradation of cellulose by cellulases and non-enzymatic proteins of T. reesei. Multiple members of the different types of cellulase enzymes - CBHs, EGs and $\beta$ glucosidases (BGLs) - degrade the crystalline cellulose synergistically to glucose. CBHs and some of the EGs are composed of a bipartite structure which includes the large catalytic domain and a smaller carbohydrate binding module (CBMs) connected via a flexible linker region. In addition, non-enzymatic proteins such as swollenin (SWO) aid in the degradation of cellulose by disrupting the crystalline structure and thus improving the accessibility of cellulose for enzymatic proteins. 


\subsection{Cellulase classification}

A number of different systems exist for the general classification of enzymes based on amino acid sequence similarities or their catalytic mechanism. The classification by the International Union of Biochemistry and Molecular Biology (IUBMB) divides proteins into sub-classes based on the nature of the reactions that they catalyze and uses a numbering code system (EC-numbers) to indicate their enzymatic activity. In this classification the T. reesei cellulases belong to the hydrolases and are found in group EC3 with CBHs (EC 3.2.1.91), EGs (EC 3.2.1.4) and $\beta$-glucosidases (EC 3.2.1.21). However, this system relies on the biochemical characterisation of a protein and to enable the prediction and classification of new enzymes in silico, a sequence-based classification was established that assigns sequences to various families according to their amino acid similarities. Carbohydrate-active enzymes, or CAZymes, are categorized into different families in the CAZy database (http://www.cazy.org, Cantarel et al., 2009). These families describe enzymes that degrade, modify, or create glycosidic bonds. The categories in the CAZy database include glycoside hydrolases (GHs; enzymes that hydrolyse or rearrange glycosidic bonds), glycosyltransferases (GTs; enzymes that form glycosidic bonds), polysaccharide lyases (PLs; enzymes with a non-hydrolytic cleavage mechanism of glycosidic bonds) and carbohydrate esterases (CEs; enzymes that hydrolyse carbohydrate esters). In addition a further section is devoted to carbohydrate binding modules (CBMs). There are several types of CBMs which are involved in the adhesion of the enzymatic module to different carbohydrates: The CBMs of cellulases (CBM family 1) are generally specific for binding to the surface of crystalline cellulose and enhance the activity of the enzyme on crystalline cellulose but not on soluble substrates (Bayer et al., 1998). The hydrolysis (GHs) and formation (GTs) of glycosidic bonds can proceed via retention or inversion of the anomeric carbon $(\mathrm{C} 1)$ of the substrate after cleavage. In an inverting enzyme the hydrolysis of a $\beta$-glycosidic bond creates a product with the a-configuration, and vice versa, whereas in retaining enzymes the $\beta$-configuration is preserved. A special case of the retaining mechanism is the "neighbouring group participation', where a side group of the substrate itself assists in the catalytic mechanism. In GHs in general two amino acids at the opposite sides of the sugar plane are the key factors for the nucleophilic attack, stabilization of the transition state and finally hydrolysis of the glycosidic bond. Often acidic side chains of the two catalytic amino acids are important for the reaction mechanism. GHs with a retaining mechanism have also commonly transglycosylating abilities and are able to form oligosaccharides from their hydrolytic reaction products when they are present in high concentrations. In contrast to that, GTs, for which so far predominantly inverting mechanisms have been reported, use activated carbohydrate monomers (e.g. UDP-activated sugars for cell wall biosynthesis) to create glycosidic bonds and thus long carbohydrate chains. Cellulases can be found in several GH families and they are specific for cleaving the $\beta(1 \rightarrow 4)$ bonds of cellulose. Interestingly both, $\mathrm{CBHs}$ and EGs are found within the same family (see also Table 1). The large numbers of three-dimensional structures of GH enzymes that have accumulated during the last 15 years have so far largely verified that members of a GH family share the same overall protein fold, a common catalytic site motif, and the same reaction mechanism, i.e. retaining or inverting. For some families only one enzymatic activity has so far been reported, whereas in other families a multitude of different enzymatic activities can be found.

The CAZy database has been online since 1998 and this resource turned out to be extremely valuable for the annotation of novel genome sequences in order to elucidate the carbohydrate degradation potential of an organism by bioinformatic means. As a 
consequence this sequence-based classification system has been widely accepted and is applied for all organisms, ranging from archaea to bacteria, fungi, plants, animals and humans. As a further consequence of the general acceptance of the CAZy classification, the T. reesei cellulases were renamed. For example the cellobiohydrolase $\mathrm{CBH} 1 / \mathrm{CBHI}$ is now CEL7A, named by its activity CEL (for cellulase), 7 for the GH family and A denoting that this was the first reported family 7 cellulase from this organism. Table 1 summarizes the corresponding "old" and "CAZy" designations for the components of the T. reesei cellulase system.

\begin{tabular}{|c|c|c|c|c|c|c|}
\hline $\begin{array}{l}\text { GH } \\
\text { family }\end{array}$ & $\begin{array}{c}\text { CAZy } \\
\text { nomenclature }\end{array}$ & $\begin{array}{c}\text { Previous } \\
\text { designation }\end{array}$ & $\begin{array}{l}\text { Cellulase } \\
\text { type }\end{array}$ & $\begin{array}{c}\text { Size in } \\
\text { amino } \\
\text { acids }\end{array}$ & $\begin{array}{l}\text { Position } \\
\text { of CBM }\end{array}$ & $\begin{array}{l}\text { Stereo- } \\
\text { selectivity }\end{array}$ \\
\hline 1 & CEL1A & BGL2 & $\beta$-glucosidase & 466 & - & Retaining \\
\hline 1 & CEL1B & & $\beta$-glucosidase ${ }^{+}$ & 484 & - & Retaining \\
\hline 3 & CEL3A & BGL1 & $\beta$-glucosidase & 744 & - & Retaining \\
\hline 3 & CEL3B & & $\beta$-glucosidase ${ }^{+}$ & 874 & - & Retaining \\
\hline 3 & CEL3C & & $\beta$-glucosidase ${ }^{+}$ & 833 & - & Retaining \\
\hline 3 & CEL3D & & $\beta$-glucosidase ${ }^{+}$ & 700 & - & Retaining \\
\hline 3 & CEL3E & & $\beta$-glucosidase ${ }^{+}$ & 765 & - & Retaining \\
\hline 5 & CEL5A & EG2 & endoglucanase & 397 & $\mathrm{~N}$ & Retaining \\
\hline 5 & CEL5B & & endoglucanase $^{+}$ & 438 & $\begin{array}{c}\text { GPI } \\
\text { anchor }\end{array}$ & Retaining \\
\hline 6 & CEL6A & $\mathrm{CBH} 2$ & cellobiohydrolase & 447 & $\mathrm{~N}$ & Inverting \\
\hline 7 & CEL7A & $\mathrm{CBH} 1$ & cellobiohydrolase & 497 & $\mathrm{C}$ & Retaining \\
\hline 7 & CEL7B & EG1 & endoglucanase & 436 & $\mathrm{C}$ & Retaining \\
\hline 12 & CEL12A & EG3 & endoglucanase & 218 & - & Retaining \\
\hline 45 & CEL45A & EG5 & endoglucanase & 270 & $\mathrm{C}$ & Inverting \\
\hline 61 & CEL61A & EG4 & endoglucanase & 344 & $\mathrm{C}$ & Not known \\
\hline 61 & CEL61B & & Endoglucanase (?)\# & 249 & - & Not known \\
\hline 74 & CEL74A & EG6 & $\begin{array}{c}\text { endoglucanase/ } \\
\text { xyloglucanase* }\end{array}$ & 818 & $\mathrm{C}$ & Inverting \\
\hline
\end{tabular}

Table 1. The cellulose degrading enzyme system of T. reesei

+ according to GH family prediction; \# no hydrolytic activity (Harris et al., 2010);

* has probably xyloglucanase activity according to $\mathrm{GH}$ family prediction

\subsection{A comparative genomic view on $\boldsymbol{T}$. reesei cellulases and related enzymes}

Efforts to clone different cellulolytic components of $T$. reesei have in the last decades resulted in the identification of the major components of its cellulase system including the two CBHs, different EGs and B-glucosidases (Table 1). However, a survey of the full potential of $T$. reesei as a biomass-degrading enzyme producer became only possible by sequencing the genome of strain QM6a. Unexpectedly, in view of the fact that T. reesei is an efficient plant polysaccharide degrader and important model for microbial cellulose and hemicellulose degradation, analysis of the genome sequence of T. reesei QM6a revealed that this fungus has actually a relatively small set of cellulases - especially the limited number of CBHs and 
EGs was surprising-, hemicellulases and other plant cell wall degrading enzymes in comparison to other filamentous fungi (Martinez et al., 2008). These findings indicated that at least part of the secret of $T$. reesei's success lies in its efficient induction system of cellulase gene transcription and in its extremely high cellulase production and secretion capacities. The so far described components of the $T$. reesei cellulolytic system include: two $\mathrm{CBHs}$ (CEL6A and CEL7A), and eight EGs (CEL5A, CEL5B, CEL7B, CEL12A, CEL45A, CEL61A, CEL61B and CEL74A). In addition, seven $\beta$-glucosidases have so far been reported in $T$. reesei (CEL1A, CEL1B, CEL3A, CEL3B, CEL3C, CEL3D, CEL3E) and according to the predictions in the CAZy database several further candidate $\beta$-glucosidases can be found in the $T$. reesei genome.

With a total of ca. $200 \mathrm{GH}$ encoding genes, T. reesei has already fewer $\mathrm{GH}$ than phytopathogenic fungi (Magnaporthe grisea and Fusarium graminearum) and in general, it has the fewest cellulases and the smallest set of hemicellulases and pectin degrading enzymes of all species able to degrade plant cell walls by a hydrolytic attack. In addition, the number of CBMs, which are involved in substrate recognition and binding of enzymes involved in plant polysaccharide depolymerisation, is the smallest among the Sordariomycetes. The CAZomes which beside GH also comprise the other groups of CAZymes are summarized for $T$. reesei and two further sequenced Trichoderma species in comparison to other fungi in Table 2.

\begin{tabular}{|l|c|c|c|c|c|}
\hline \multicolumn{1}{|c|}{ Fungus } & GH & GT & PL & CE & CBM \\
\hline Trichoderma reesei & 193 & 93 & 5 & 17 & 41 \\
\hline Trichoderma atroviride & 242 & 96 & 8 & 25 & 62 \\
\hline Trichoderma virens & 256 & 98 & 6 & 25 & 87 \\
\hline Aspergillus nidulans & 251 & 91 & 21 & 31 & 41 \\
\hline Aspergillus niger & 243 & 110 & 8 & 24 & 40 \\
\hline Gibberella zeae & 247 & 102 & 21 & 44 & 64 \\
\hline Magnaporthe grisea & 232 & 92 & 5 & 48 & 65 \\
\hline Neurospora crassa & 173 & 76 & 4 & 23 & 42 \\
\hline Penicillium chrysogenum & 216 & 101 & 9 & 22 & 49 \\
\hline Postia placenta & 248 & 102 & 8 & 25 & 34 \\
\hline Saccharomyces cerevisiae & 46 & 68 & 0 & 3 & 12 \\
\hline
\end{tabular}

Table 2. CAZome comparison of T. reesei with other fungi (data adapted from Kubicek et al., 2011). GH: glycoside hydrolases, GT: glycosyltransferases, PL: polysaccharide lyasas, CE: carbohydrate esterases, CBM: carbohydrate binding modules.

The analysis of the genomes of the two mycoparasitic Trichoderma species, T. atroviride and T. virens (Kubicek et al., 2011), showed that the number of identified cellulases is not significantly increased in these fungi either, suggesting that the observed low variety of cellulases is a common feature of the genus Trichoderma (Tables 3 and 4). T. atroviride and T. virens have slightly more cellulases than $T$. reesei with additional one and two, respectively, members of family GH12. T. virens has in addition another GH45 cellulase containing a CBM1 at the C-terminus. Although only two GH61 proteins have so far received attention in cellulose degradation, all three Trichoderma spp. possess another GH61 protein, which could also be involved in plant biomass degradation, but has not been characterized so far. The 
GH5 cellulase CEL5B has in all three investigated Trichoderma species a putative GPI (Glycophosphatidylinositol)-anchor at the C-terminus, which would render this protein bound to the plasma membrane/fungal cell wall. Families GH5 and GH3 contain, besides cellulases and $\beta$-glucosidases, also many proteins with other enzymatic activities (e.g. $\beta-1,6$ glucanases, $\beta$-xylosidases, mannanases, etc.) and a relatively high number of these enzymes is found in the three analysed Trichoderma spp. (11-17 members/GH family/species). A more in-depth analysis and biochemical characterizations will be necessary to reveal the specific activities of members of these families. In contrast to that, the enzymatic characteristics of other GH families are very specific for cellulose degradation, e.g. only two GH7 proteins are found in all three sequenced Trichoderma spp. and both of them are prominent members of the cellulase-system, one being CEL7A and the other CEL7B.

\begin{tabular}{|c|c|c|c|c|c|c|c|}
\hline Fungus & GH5 $^{*}$ & GH6 & GH7 & GH12 & GH45 & GH61 & Total \\
\hline T. reesei & 2 & 1 & 2 & 2 & 1 & 3 & $\mathbf{1 1}$ \\
\hline T. atroviride & 2 & 1 & 2 & 3 & 1 & 3 & $\mathbf{1 2}$ \\
\hline T. virens & 2 & 1 & 2 & 4 & 2 & 3 & $\mathbf{1 4}$ \\
\hline
\end{tabular}

Table 3. Comparison of CBHs and EGs in the three sequenced Trichoderma species based on genome annotation data (data adapted from Kubicek et al., 2011). * Numbers indicate only putative cellulases from family GH5.

Beside the insight in the celluloytic potential of the three Trichoderma spp, the genome comparison provides also valuable information about the other plant cell wall degrading enzymes and lists different possibilities to improve the plant cell wall degrading potential of $T$. reesei with enzymes from these two closely related species. The general low pectin degrading potential of all three fungi indicates that they are not equipped with enzymes which are necessary to attack living or intact plants but are better adapted to decompose dead and decaying plant matter. Within the group of hemicellulases, the number of xylanases in $T$. reesei is similar to the two mycoparasites, although $T$. virens has two GH10 proteins whereas $T$. reesei and T. atroviride have only one, and further one of the GH11 members of T. atroviride has a CBM1 at the C-terminus, but no CBMs are found in the respective proteins of $T$. reesei and $T$. virens. Furthermore, T. atroviride and T. virens have slightly more a-L-arabinofuranosidases (in families GH43, GH51 and GH62), a-glucuronidases (GH67) than T. reesei and posses in addition also endo-acting a-arabinanases (GH93).

A relatively low capacity and flexibility to decompose pectin is observed in all three sequenced Trichoderma species based on the identified enzymes of families GH28, 78, 88, and 105, families PL1, 3 and 4, and families CE8 and 12, all directly acting on polygalacturonan and rhamnogalacturonan or their respective degradation products. Equally, the number and nature of pectin side-chain degrading enzymes (GH43, 51, 53, and 54) is lower than in other fungi; e.g. Aspergillus niger has already at least 39 genes encoding enzymes involved in the depolymerisation of the backbone of pectin (Martens-Uzunova and Schaap, 2009) and in addition several genes encoding enzymatic activities required for the degradation of the arabinan and arabinogalactan side chains. In contrast to that, T. reesei has only a total of 6 pectinolytic enzymes, whereas $T$. virens and $T$. atroviride have a slightly better pectin degradation machinery and possess at least 15 pectinolytic enzymes. Thus, the numbers of pectin degrading enzymes (GH78, 88, 105, PL1, CE8) are slightly enriched in these two fungi in comparison to $T$. reesei. These additional proteins could constitute a small albeit important 
difference facilitating the attachment to roots or the displacement of hyphae in the pectinrich intercellular space of plants, thereby deepening fungal-plant interactions of $T$. virens and T. atroviride.

\begin{tabular}{|c|c|c|c|c|c|c|c|c|c|c|c|c|c|c|}
\hline GH family & $\mathbf{1 0}$ & $\mathbf{1 1}$ & $\mathbf{2 6}$ & $\mathbf{2 9}$ & $\mathbf{3 9}$ & $\mathbf{4 3}^{*}$ & $\mathbf{5 1}^{*}$ & $\mathbf{5 3 ^ { * }}$ & $\mathbf{5 4}$ & $\mathbf{6 2}$ & $\mathbf{6 7}$ & $\mathbf{7 4}$ & $\mathbf{9 3}$ & Total \\
\hline T. reesei & 1 & 4 & 0 & 0 & 1 & 2 & 0 & 0 & 2 & 1 & 1 & 1 & 0 & $\mathbf{1 3}$ \\
\hline T. atroviride & 1 & 4 & 0 & 0 & 2 & 5 & 1 & 0 & 2 & 2 & 2 & 1 & 3 & $\mathbf{2 3}$ \\
\hline T. virens & 2 & 4 & 2 & 0 & 1 & 3 & 0 & 0 & 2 & 3 & 2 & 1 & 1 & $\mathbf{2 1}$ \\
\hline
\end{tabular}

Table 4. Comparison of hemicellulases in the three sequenced Trichoderma species based on genome annotation data (data adapted from Kubicek et al., 2011). * Members of these GH families are also involved in pectin side chain degradation.

\subsection{New players in cellulose degradation}

In addition to the classical cellulases, a number of non enzymatic proteins substantially aid in cellulose degradation. One example for such a non-enzymatic protein is swollenin (SWO1) that modifies cellulose by disrupting its crystalline structures and thereby enhances its hydrolysis (Saloheimo et al., 2002). Swollenin has in addition to an N-terminal CBM1 an expansin domain. These domains are usually found in plant proteins that aid in loosening up the cell wall structure of plants and it has been shown that SWO1 is important for the fungal cellulose degradation process because it is involved in opening up the rigid structure of crystalline cellulose and thus makes the substrate more accessible for cellulases (see also Fig. 1). Trichoderma spp. have additional 3-4 proteins with expansin-like domains though these proteins have no CBMs. In addition, no transcriptional upregulation of the respective genes was found under cellulase-inducing conditions indicating that they might have other roles (Verbeke et al., 2009).

There certainly are several uncovered enzymatic or protein activities still hidden in the genome of $T$. reesei. The genes encoding CIP1 and CIP2 are strongly expressed under cellulase-inducing conditions. CIP2 was only recently described to encode a CE15 glucuronoyl esterase, probably cleaving the ester linkage between 4-O-methyl-D-glucuronic acid of glucuronoxylan and lignin alcohols (Li et al., 2007). The function of CIP1 is not known yet. BLAST searches of CIP1 in public databases show that it is similar to glycosyl hydrolases found in bacteria but which are not yet characterized in detail, indicating that CIP1 could have a novel undescribed enzymatic activity or mechanism.

The recalcitrance and crystallinity of the biomass is a major obstacle for the cellulolytic enzyme set of $T$. reesei. In its natural environment biotic and abiotic factors such as other microorganisms, changes in ambient temperature and humidity aid in loosening up the rigid structure of cellulosic material to render it more accessible for $T$. reesei's cellulases and hemicellulases. However, for biotechnological processes this obstacle needs to be overcome by other means. This problem can be approached from two sides: (a) by improving the enzyme mix and (b) by optimizing the pretreatment of the cellulosic biomass. Strong research efforts are ongoing in both of these fields to overcome the recalcitrance of cellulosic biomass and it will be important to combine them in their most effective way. Advanced modeling and microscopy techniques are applied to increase the understanding of enzyme-substrate interactions and to improve the enzymatic activity of existing cellulases by protein engineering approaches with respect to thermostability and 
activity on insoluble substrates. However, in addition to these important aspects, there is a large enzymatic potential still hidden within the diversity of the fungal kingdom and the ongoing fungal genome sequencing efforts are just beginning to unravel the yet undiscovered potential of so far unknown enzymes that could aid in strongly improving the enzyme mix.

The classification of glycoside hydrolase families is based on amino acid similarities, which implies structural relationship and thus similar enzymatic mechanisms. However, detailed investigation of the sequence and 3D structure of some proteins can reveal that they might not be catalytically active - or at least not use the same catalytic mechanism as other proteins in the same GH family - as was recently reported for GH 61 proteins (Harris et al., 2010; Karkehabadi et al., 2008). While endoglucanase activity was reported for some GH 61 members, e.g. CEL61A from T. reesei and CEL61A from Aspergillus kawachii, analysis of the crystal structure of another GH61 member, CEL61B from T. reesei showed that there is no easily identifiable carbohydrate-binding cleft or pocket or catalytic centre of the types normally seen in GHs. Further, GH61 proteins of the thermophilic ascomycete Thielavia terrestris were shown to be capable of enhancing the activity of cellulases from T. reesei on pretreated corn stover. The respective GH61 proteins lacked measurable hydrolytic activity by themselves but in the presence of various divalent metal ions they significantly reduced the total protein loading required to hydrolyze lignocellulosic biomass. Structural analysis of the T. terrestris GH61E protein further supported the lack of a hydrolytic mechanism, as no evidence for clustering of conserved catalytic acidic residues that are present in almost all known glycoside hydrolases was found. T. terrestris GH61E has an important metal ionbinding site, which was investigated by mutagenizing those residues directly or indirectly involved in metal binding. Mutation of the directly interacting His-1 to Asn or His-68 to Ala resulted in a completely inactive protein. A structural comparison search showed that the known structure most similar to T. reesei Cel61B is that of CBP21 from the Gram-negative soil bacterium Serratia marcescens. For $T$. terrestris GH61E also significant structural similarity was found. S. marcescens CBP21 is a member of the CBM family 33 proteins. A polar surface patch which is highly conserved in that structural family has been identified in CBP21 and was shown to be involved in chitin binding (Vaaje-Kolstad et al., 2004). Chitin is a cellulose derivative where the 2-hydroxy group has been substituted with an acetamido group and is the second most abundant biopolymer after cellulose. The crystallinity and insolubility of cellulose and chitin in water are major obstacles for the efficient enzymatic degradation of these abundant biopolymers. Most interestingly, CBP21 was recently shown not only to possess chitin-binding activities, but also to be enzymatically active on chitin. CBP21 has a new enzymatic mechanism that introduces chain breaks by generating oxidized ends and thus opening up the rigid structure of crystalline chitin and making it accessible polysaccharide material for hydrolysis by normal glycoside hydrolases (Vaaje-Kolstad et al., 2010). The products of this reaction were identified as chitin oligosaccharides with a normal sugar at the nonreducing end and an oxidized sugar at the reducing end. In the presence of a reductant such as ascorbic acid, CBP21 boosted chitinase efficiency on crystalline $\beta$-chitin to much higher levels than previously observed. Thus, the reaction catalyzed by CBP21 comprises a hydrolytic step and an oxidation step and the authors suggested naming CBP21 a "chitin oxidohydrolase." CBP21 catalysis was found to be inhibited by EDTA, and activity could be restored by adding divalent cations such as $\mathrm{Mg}^{2+}$ or $\mathrm{Zn}^{2+}$, which may bind to the conserved histidine motif in analogy to the metal-ion binding site in GH61 protein. This shows that, with more protein crystal structures to be solved in the next years, structural 
comparison might provide unprecedented, novel clues and unravel so far unknown links between different protein families.

\subsection{Cellulase production and engineering}

T. reesei is an efficient producer of cellulases and industrial production exceeds $100 \mathrm{~g}$ cellulases per liter. The highest producer in the public domain and widely used as a cellulase hyperproducer is RUT-C30 which produces $30 \mathrm{~g} / 1$. A number of industrial strains are derived from this mutant. The highest amount of cellulases reported for a certain strain was the industrial strain CL487. Interestingly, we could recently show that in contrast to the published genealogy of this mutant, the strain is in fact a progeny of RUT-C30 since it shares a number of mutations also found in RUT-C30 (Portnoy et al., 2011). Since most of the cellulase genes are regulated in a coordinated way, only the relative ratio of their expression differs in higher production mutants (Foreman et al., 2003). The CBHs CEL6A and CEL7A are the two most abundantly secreted proteins in $T$. reesei under cellulase-inducing growth conditions. These proteins are known to account for 70 to $80 \%$ of the total T. reesei cellulases whereby CEL7A typically makes up around $60 \%$ of the total secreted cellulases (Nummi et al., 1983). Other abundant components of the T. reesei cellulase complex are CEL6A (15-20\%), CEL7B and CEL5A with up to $10 \%$ each.

$\mathrm{CBHs}$ are recognized as being the most important enzyme components for cellulose conversion and considerable attention is paid to the mechanistic action of T. reesei CEL6A and CEL7A (Barr et al., 1996) with the ultimate goal of improving their performance (Zhang and Lynd, 2006). The relatively low turnover rates of cellulases, e.g. one to four per second for CEL7A (Jalak and Valjamae, 2010) present major challenges for cost-effective production of biofuels. Thus the substrate binding and catalytic residues of the CBHs have already been investigated in considerable detail (for review see Schülein, 2000), but efforts to increase the thermostability and performance of CBHs are still ongoing (Lantz et al., 2010). The action of the catalytic and carbohydrate-binding domains on crystalline cellulose was investigated with atomic force microscopy to visualize and define the role of the two domains in this process (Igarashi et al., 2009). The complete CEL7A protein moved with a velocity of ca. 3.5 $\mathrm{nm} / \mathrm{sec}$ on crystalline cellulose and interestingly, the average velocity of the sliding catalytic domain alone without CBM was similar to that of the intact CEL7A. This indicates that adsorption on crystalline cellulose through the CBM is not essential for the movement of CEL7A, and the catalytic domain alone seems to be sufficient for the sliding on the substrate. In another study, it was reported that a size reduction apparently occurred only in the width of the cellulose crystal, whereas the height remained relatively constant, indicating that CEL7A selectively hydrolyzes the hydrophobic faces of cellulose. The authors suggested that the limited accessibility of the hydrophobic faces in native cellulose may contribute significantly to the rate-limiting slowness of cellulose hydrolysis (Liu et al., 2011).

Another parameter that has an impact on cellulase performance is protein glycosylation, which can influence the function and stability of proteins. Most enzymes secreted by T. reesei are $\mathrm{O}$ - and $\mathrm{N}$-linked glycoproteins. These glycosides are attached to the enzymes during the protein maturation and secretion process and are further modified by trimming and addition of new glycosides within the different compartments of the secretory pathway before the protein is finally exported into the surrounding medium. Glycosylation and other co- and posttranslational modifications (e.g. phosphorylation, proteolytic processing, disulfide bridge formation or attachment of a GPI-anchor) and their potential effects on enzyme performance have to be taken into account when $T$. reesei cellulases are expressed in 
heterologous host systems. This is especially important when cellulases are expressed in planta or more dramatically in bacterial hosts which are in general not able to accomplish posttranslational modifications and usually are used for the intracellular production of enzymes. It is still a challenge to understand the effect of protein glycosylation on cellulase activity and to express active cellulases successfully in heterologous hosts. Expression of CEL7A was already evaluated in different classical protein expression systems, ranging from Escherichia coli to the yeasts Saccharomyces cerevisiae and Pichia pastoris and to other filamentous fungi such as Aspergillus niger var. awamori, which often are used to produce large quantities of enzymes and proteins for industrial processes (Adney et al., 2003). However, successful expression of a functional cellulase is limited due to different co- and posttranslational requirements including correct glycosylation but also the formation of disulfide bridges has to be considered. CEL7A expression in A. niger var. awamori resulted in a recombinant CEL7A which was overglycosylated in comparison to the native T. reesei enzyme. As a consequence of the $\mathrm{N}$-overglycosylation a reduced activity and increased non-productive binding on cellulose was observed (Jeoh et al., 2008). Even when produced by T. reesei, the glycosylation pattern is not uniform and depends on the fungal strain, the fermentation medium and $\mathrm{pH}$, and the secretion of other carbohydrate modifying activities into the medium (Stals et al., 2004a; Stals et al., 2004b). In addition to the impact of glycosylation in the catalytic domain on enzyme activity, the $O$-glycosylation of the linker region connecting catalytic domain and CBM was examined. In this simulation study, the $O$-glycosylation does not change the stiffness of the linker, but rather provides a $1.6 \mathrm{~nm}$ extension, thus expanding the operating range of CEL7A (Beckham et al., 2010). Understanding the expression, posttranslational modifications and even more details of the protein architecture in the context of enzyme performance of CBHs and EGs is important for the development of fuels from cellulosic biomass.

When $T$. reesei is used as a production host for heterologous proteins or large amounts of proteins, improvements in the efficiency of protein folding, quality control and transport in the secretory pathway will be necessary to maintain high level enzyme production. For the recombinant production of homologous and heterologous proteins and enzymes the corresponding genes are usually expressed under the promoter and terminator region of the major cellulases cel7a or other cellulases to guarantee a high production under cellulase inducing conditions. Attempts to produce cellulases on other carbon sources such as glucose resulted generally in lower amounts of protein produced even when the strongest available promoters were used (Nakari-Setälä and Penttilä, 1995). Various mechanisms sense the accumulation of proteins within the secretory pathway including the unfolded protein response (UPR) in the ER. UPR is mediated by the proteinkinase/endoribonuclease IRE1 which activates $\mathrm{HACl}$, a transcription factor which in turn upregulates genes involved in protein folding, glycosylation, transport, and in the degradation of misfolded proteins. UPR can also be stimulated by different chemical agents that prevent protein folding or transport. Using such agents, a novel kind of secretion stress termed repression under secretion stress (RESS) was detected in $T$. reesei which downregulates the transcript levels of genes encoding cellulases but also of secreted proteins in general and thereby reduces both the expression of the cellulases and the recombinant protein driven by cellulase promoters (Pakula et al., 2003).

\section{Regulation of cellulase expression}

The quest of $T$. reesei to most efficiently detect cellulose in the environment, to degrade the insoluble substrate by producing different cellulases, transport the soluble break-down 
products from the surrounding through the cytoplasmic membrane into the cell and subsequently assimilate these sugars, is an essential process to survive. However, to be able to compete with other microorganisms, $T$. reesei has also to be flexible and immediately respond and adapt to changes in the nutrient composition of the environment. When exposed to a mixture of carbon sources, T. reesei will utilize the best carbon and energy source available and downregulate the expression of genes which are involved in the degradation of less favourable and complex carbon sources such as cellulose. Degradation of individual carbon sources present in complex mixtures follows a mainly energy driven hierarchy, although adaptation of e.g. saprobic or plant pathogenic fungi to their habitats has resulted in species specific carbon source priorities. Especially genes encoding enzymes involved in polysaccharide degradation are tightly regulated since their synthesis, co- and posttranslational modifications and export through the secretory pathway requires a high energy input by the fungus. Sophisticated mechanisms including carbon sensing and signalling ensure an assimilation hierarchy and two major control circuits i.e. specific induction and general carbon catabolite repression (CCR) control cellulase gene expression and enable an economic production of cellulases. Since $T$. reesei and most of the other microorganisms are particularly adapted to glucose, the most abundant monosaccharide in nature, this CCR is often termed simply glucose repression although other carbon sources are also able to provoke CCR.

The cellulolytic system of $T$. reesei is subject to multiple levels of control whereby most of the regulation happens at the level of transcription. Another characteristic of cellulase expression is that the different cellulase encoding genes are co-regulated, which means that they are expressed under all conditions at the same relative amounts (Foreman et al., 2003; Ilmen et al., 1997). As the prime function of cellulases is the hydrolysis of cellulose and thus to provide the fungal cells with soluble oligomers as carbon source and for energy production, these enzymes are specifically formed in the presence of cellulose and soluble derivatives thereof. The additional presence of other more easily metabolisable monosaccharides leads to cellulase repression even in the presence of an inducer. In T. reesei and other fungi CCR is ultimately mediated by the transcription factor CRE1 (Fig. 2). The CRE1 binding motif in the promoter regions of the cellulase and xylanase genes is $5^{\prime}$ SYGGRG-3' but its functionality depends also on the context within the promoter region. The in vivo functionality of the CRE1 binding sites have been demonstrated for the cellulase cel7a promoter and the xylanase xyn 1 promoter. Removal of the CRE1 binding sites led to a basal level of cellulase expression on D-glucose indicating that these genes are now carbon catabolite derepressed (Ilmen et al., 1996a; Mach et al., 1996). A number of these functional CRE1 binding sites are characterized by two closely spaced 5'-SYGGRG-3 motifs and it is assumed that direct CRE1 repression occurs mainly through this double motif. CCR can act on cellulase gene expression on different levels either directly by CRE1 (Dowzer and Kelly, 1991; Ilmen et al., 1996b) which represses individual cellulase expression or transcription of its activators, or by inducer exclusion. Inducer exclusion is a regulatory phenomenon whereby other carbohydrates inhibit uptake of the inducing carbon source. This can be a consequence of the inhibition of inducer uptake through a specific permease by a structurally related sugar or by CRE1-mediated repression of the gene encoding a specific permease of the inducible system. Another possibility would be that formation of the inducer is inhibited within the cell which also prevents induction. 


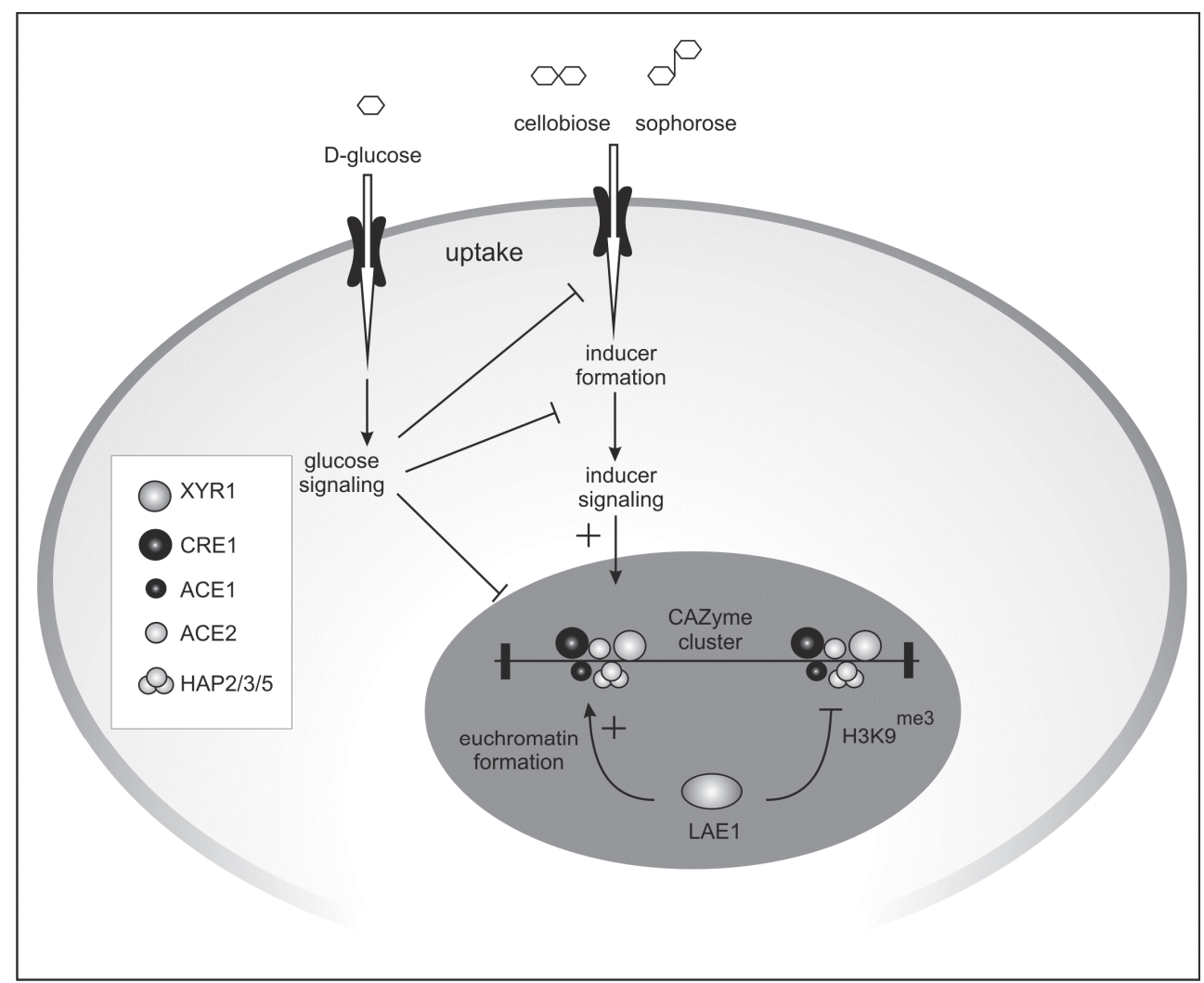

Fig. 2. Regulation of cellulase gene expression in T. reesei. Regulation of cellulase genes is accomplished on the transcriptional level by carbon catabolite repression (indicated here by D-glucose) or specific induction by cellulose breakdown (cellobiose) or transglycosylation (sophorose) products. CCR can act on different levels including inducer uptake, inducer formation, and direct repression of cellulase and transcriptional activator gene expression. Positive regulation is accomplished via the transcriptional activators XYR1, ACE2 and the HAP complex and negative regulation via CRE1 and ACE1. In addition cellulase expression in the CAZyme clusters is also regulated on the chromatin level by the putative proteinmethyltransferase LAE1. Potential targets are euchromatin formation and H3K9 methylation.

Since the expression of a vast majority of the cellulase genes in T. reesei does not occur during growth on glucose, one of the earliest attempts to improve cellulase production was towards a release from carbon catabolite repression (see the following section). One of the best cellulase producers in the public domain, the carbon catabolite derepressed strain RUT C30, indeed contains a truncation in the cre1 gene (Ilmen et al., 1996b; Seidl et al., 2008), thus indicating the importance of carbon catabolite derepression for cellulase formation. However, relief from carbon catabolite repression alone is not sufficient for high cellulase production, as cultivation on glucose or other carbon sources results only in low cellulase levels, which do not match cellulase levels under inducing conditions, as confirmed by the deletion of cre 1 in wild-type 
and different mutant strains. These results establish cre1 as one of the main targets for strain improvement but also indicate that cellulase hyperproduction is still inducer dependent (Nakari-Setälä et al., 2009). The regulatory pathways by which the presence of D-glucose triggers carbon catabolite repression are still only poorly understood in filamentous fungi. In the yeast $S$. cerevisiae, D-glucose and D-fructose phosphorylating enzymes are involved in Dglucose sensing and carbon catabolite repression, whereby hexokinase 2 contributes to glucose repression. The situation seems to be different in filamentous fungi. In A. nidulans mutations in both the gluco- and hexokinase are necessary for a CreA (A. nidulans CRE1 homologue)mediated carbon catabolite derepression on D-glucose which suggests a compensatory effect of these two proteins in single mutants (Flipphi et al., 2003). Similarly, in the T. reesei glucokinase and hexokinase deletion strains carbon catabolite repression on D-glucose is maintained and only the double deletion strains are derepressed.

Since carbon catabolite derepression alone is not sufficient for high cellulase production, it is of fundamental interest for high enzyme production to elucidate the molecular basis on how $T$. reesei senses the presence of cellulose and initiates cellulase induction. High cellulase formation requires the presence of an inducing carbon source, which can be derived from cellulose, e.g. the two disaccharides sophorose and cellobiose. For the initial inducer formation it is assumed that a low basal level of cellulases is produced which attack the insoluble cellulose and form the inducer or inducer precursors by releasing small amounts of di- and oligosaccharides. These oligosaccharides are taken up and can then induce further cellulase biosynthesis (Carle-Urioste et al., 1997). CEL6A was found to be the predominant cellulase on $T$. reesei conidia and a cel6a knock out strain exhibited a pronounced delay in initiating growth on cellulose and cellulase transcription (Seiboth et al., 1992). The additional deletion of the second $\mathrm{CBH}$-encoding gene cel7a led to strains which could not initiate growth on cellulose (Seiboth et al., 1997) without the addition of a soluble inducer for cellulase induction. These studies provide significant support for the role of conidiabound cellulases for the primary attack on cellulose to provide soluble cellulose break-down products which initiate growth and inducer formation.

Sophorose (2-O- $\beta$-D-glucopyranosyl-a-D-glucose) is the strongest cellulase-inducing sugar and is formed by $T$. reesei during cellulose hydrolysis by the cellulase system through transglycosylation reactions (Gritzali and Brown, 1979; Vaheri et al., 1979). It is assumed that sophorose formation requires the action of $\beta$-glucosidase(s). In addition to this cellulosederived inducer a few other inducers including the disaccharide lactose ( $\beta$-Dgalactopyranosyl-( $1 \rightarrow 4)$-D-glucose) and L-sorbose, the only monomeric sugar, are known. L-sorbose induces high cellulase transcript levels but it cannot be effectively applied in industrial fermentations since it also severely affects cell growth and is hardly metabolized by the cell. Due to the fact that lactose is soluble and by far cheaper than the other two inducing disaccharides cellobiose and sophorose, it is often used as a soluble carbon source in $T$. reesei cellulase and recombinant protein fermentations which has been reviewed by us previously (Kubicek et al., 2009; Seiboth et al., 2007). The obligatory presence of an inducer for cellulase gene expression implies tight regulation of their promoter regions. The different cellulase genes are generally regulated in a coordinated way and at least three transcriptional activators including XYR1, ACE2 the HAP2/3/5 complex, as well as the two repressors CRE1 and ACE1 are involved in their regulation (Fig. 2, Aro et al., 2005, Kubicek et al., 2009). Amongst these, XYR1 is clearly the major cellulase activator and indispensable for cellulase expression. It is an orthologue of the $x \ln R$ gene of $A$. niger and consensus sequences for XYR1 have been found in all inducible T. reesei (hemi)cellulase promoters 
investigated so far. XYR1 is a zinc binuclear cluster protein which binds to a GGCTAAmotif. Deletion of xyr1 eliminates cellulase induction on cellulose and sophorose, thus proving its essential role in the induction process. In addition it regulates xylanases, $\beta$ xylosidase and also some a-L-arabinofuranosidases (Akel et al., 2009; Stricker et al., 2006). ACE2 is a coactivator whose influence is specific for growth on cellulose: ace 2 deletion reduces cellulase activity to $30-70 \%$ during growth on cellulose but does not affect induction by sophorose. Expression from the cel6a promoter is dependent on a CCAAT box bound by the HAP2/3/5 protein complex and it is assumed that this CCAAT sequence plays a role in the opening of the chromatin structure necessary for high level transcriptional activation. ACE1 is a repressor of cellulase gene transcription and binds to the sequence 5'-AGGCA-3'. Deletion of ace 1 increased the expression of cellulase and xylanase genes in sophorose and cellulose induced culture. ACE1 represses also transcription of xyr1 (Mach-Aigner et al., 2008). A strain deleted in both ace1 and ace 2 expressed cellulases and xylanases similar to the $\triangle a c e 1$ strain. An interesting difference to the regulation of cellulases and hemicellulases to $A$. niger by $\mathrm{X} \operatorname{lnR}$ is that $\mathrm{D}$-xylose induces only xylanases but not cellulase in T. reesei (Ilmen et al., 1997). This would implicate that the substrate-unspecific activator XYR1 is fine tuned by more specific transcriptional regulators or other signals.

One of the most interesting results from the analysis of the genome sequence of $T$. reesei QM6a was that 130 of the 316 CAZyme genes, including e.g. the two CBH-encoding genes, are located in 25 distinct clusters (Martinez et al., 2008). These CAZyme clusters were found in non-conserved genome regions to other closely related fungi. The precise preservation of the order of genes on a chromosome of related species is described by the term synteny. During species evolution this synteny is often lost due to rearrangements of the gene order in the chromosomes or between chromosomes, resulting in large gaps between syntenic blocks. In the interjacent non-syntenic regions often species-specific characteristics are found which are important for the adaption of the species to its environment. These non-syntenic CAZyme clusters contain also a number of genes encoding proteins involved in secondary metabolism such as polyketide synthase (PKS) or nonribosomal peptide synthase (NRPS). One conclusion from this gene clustering would be that $T$. reesei is able to regulate GHs and secondary metabolites in a coordinate manner and would enable $T$. reesei to fend off competition for nutrients during polysaccharide degradation by producing toxic substances. It is long established that cellulases and hemicellulases are expressed in a coordinate manner and the question arises if their accessibility on a transcriptional level could be enhanced even further by wide domain regulators, which control the accessibility of these regions by chromatin remodelling for the activation of more specific gene regulators such as e.g. the cellulaseand xylanase-regulator XYR1. Clustering of genes encoding enzymes involved in the biosynthesis of secondary metabolites is often found in fungi including Aspergillus spp. and regulated beside pathway-specific transcription factors also at an upper hierarchic level by global epigenetic control mechanisms. It was recently established that some of these gene clusters are regulated by a putative protein methyltransferase LaeA which is considered as a master regulator of secondary metabolism in Aspergilli and other species (Palmer and Keller, 2010). Although the exact role of LaeA is unclear, it is suggested that LaeA might control the accessibility of binding factors to chromatin regions of secondary metabolite clusters because the S-adenosyl methionine binding site of LaeA prevents heterochromatin maintenance of some clusters. Although the mechanism leading to these secondary metabolite gene clusters in Aspergilli and other fungi might be different from 
the CAZyme clusters, the role of the orthologous LAE1 in T. reesei was tested. The results show that the presence of LAE1 is required for the expression of the major cellulase and hemicellulase genes, and that its absence resulted in the inability to grow on cellulose. Expression of lae1 under a strong constitutive promoter resulted in significantly increased cellulase gene transcription and cellulase formation. These data provide an experimentbased explanation of the advantage for clustering of cellulases in the genome of T. reesei and illustrate that chromatin regulation is a suitable target for strain improvement (Seiboth et al., ms submitted). In the case of secondary metabolite biosynthetic genes, clustering has been suggested to reflect their evolutionary history (Keller et al., 2005; Zhang et al., 2004). In the"selfish cluster" hypothesis it is suggested that selection occurs by promoting the maintenance of the cluster as a unit, by e.g. horizontal transfer events (Walton, 2000). However, there is no evidence or indication for horizontal gene transfer for the major cellulase and hemicellulases found in the CAZyme clusters and it is therefore likely that these CAZyme clusters are maintained by the operation of coregulation mechanisms which is essentially what is observed for cellulases and hemicellulases which are coinduced by similar substrates and controlled by a set of similar transcriptional regulators. Interestingly, xyr1 itself is located in one of the CAZyme clusters, and downregulated in the $\Delta l a e 1$ strain, which indicates that LAE1 controls both, accessibility of the cellulase genes and their major transcriptional activator. The signalling pathway by which the presence of the cellulase inducer is communicated to the $T$. reesei transcriptional machinery is not known yet. Its identification may also shed light on how LAE1 receives the signal so that cellulase gene transcription can be activated.

\section{Strain improvement in $T$. reesei}

One of the key issues in fungal strain breeding is the generation of improved producer strains in terms of enzyme yield. In the past this has traditionally been achieved by a combination of classical mutagenesis during which the fungus was exposed to different mutagens such as X-rays, $\gamma$-rays, UV rays, or chemicals, including $N$-methyl- $N$ '-nitro- $N$ nitrosoguanidine (NTG) and ethyl methanesulfonate (EMS), in combination with different screening procedures to isolate cellulase-overexpressing strains. Classical mutagenesis is a common tool that has been successfully applied for many microorganisms, including fungi, to improve the production of various industrial enzymes (glucoamylase, lipase or cellulase). A prerequisite in such strain improvement programs is, of course, that the microorganism already produces the enzyme(s) of choice. It is a peculiarity of $T$. reesei that all these cellulase high-producing strains generated by classical mutagenesis and used today in research or by the major enzyme manufacturers are derived from strain QM6a from the Solomon Islands. However, the availability of sophisticated gene manipulation methods and the recent decoding of the genome sequence of $T$. reesei enable us to introduce molecular genetic tools into such programs. One approach to better understand the biology underlying cellulase hyperproduction is the analysis of improved producer strains derived from classical mutagenesis programs. Until recently, only a few data were available on the genomic alterations that occurred in the strains undergoing strain improvement procedures. With the publication of the genome sequence of strain QM6a and the development of high-throughput methods such as massively parallel DNA sequencing and comparative genomic hybridization (CGH), it is now possible to identify the genomic changes that occurred in the different mutant lines. 


\subsection{A short history of the main $T$. reesei strain improvement programs}

Over the past decades, academic and industrial research programs have produced many different $T$. reesei strains by random mutagenesis in combination with appropriate selection regimes (reviewed by Harman and Kubicek, 1998) whose cellulase production exceeds by far the level of the original isolate QM6a. By 1979, classical mutagenesis programmes had led to the development of mutant strains with an up to 20 times higher productivity compared to the original isolate, and nowadays, improved producer strains are reported to secrete more than 100 grams of cellulases per litre in industrial fermentations. The first reported cellulase mutant strain was isolated at Natick Laboratories by irradiating conidia of QM6a in a linear particle accelerator (Fig. 3). QM9123 produced twice as much cellulases as its parental strain on cellulose-containing media. Further irradiation resulted in strain QM9414 which produced up to four times higher levels of cellulases than QM6a. QM9414 is an early cellulase mutant which is used today in research and was also often used as the parental strain in improvement programs. At Rutgers University a separate line of highproducing mutants was generated. Among these strains, RUT-C30 has become the most frequently used cellulase hyperproducer in the public domain. Montenecourt and Eveleigh prepared two mutant lines which led to the hypercellulolytic strains RUT-C30 and RL-P37 (Montenecourt and Eveleigh, 1977; Montenecourt and Eveleigh, 1979), RUT-C30 was generated by three rounds of mutagenesis and selection with the ultimate goal of isolating a carbon catabolite derepressed strain. In the first step, UV mutagenesis and selection for the ability to hydrolyze cellulose under carbon catabolite repressing conditions led to strain M7 which was further mutagenised by an NTG treatment under carbon catabolite repression conditions. This led to the isolation of strain NG14, which already showed a strong increase in secreted protein and cellulase activity but still showed considerable catabolite repression. NG14 was subjected to another round of UV mutagenesis and screening for elevated cellulose hydrolysis levels and resistance to 2-deoxyglucose to eliminate carbon catabolite repression leading to RUT-C30. 2-deoxyglucose is a non-metabolizable analogue of glucose in which the 2-hydroxyl group is replaced by a hydrogen atom. This compound is taken up by the cell but cannot undergo further glycolysis and the hexokinase enzyme traps this substance in most cells producing 2-deoxyglucose-6-phosphate which exhibits CCR. The resulting strain RUT-C30 produces twice as much extracellular protein as its parental strain NG14, reaching more than $30 \mathrm{~g} / \mathrm{L}$ production in industrial fermentations and is carbon catabolite derepressed.

In the last years three major genetic changes in RUT-C30 were revealed. The first discovered mutation is a truncation in the cre1 gene, the key transcription regulator of carbon catabolite repression in fungi (Ilmen et al., 1996b; Seidl et al., 2008). This is not surprising, since the elimination of carbon catabolite repression was one of the main targets during the mutagenesis program. It was recently shown that the deletion of either the complete cre 1 gene or its replacement with the truncated version of RUT-C30 has largely the same physiological effect, indicating that the truncated cre1 gene is practically a null allele (Nakari-Setälä et al., 2009). The second mutation detected in RUT-C30 was a frame-shift mutation in the gene $g l s 2 a$, encoding the glucosidase a-subunit, resulting in a truncated gene product (Geysens et al., 2005). This protein is involved in the structural modification of $\mathrm{N}$ linked oligosaccharides present on glycoproteins and in the quality control mechanisms of polypeptides such as cellulases which are traversing the endoplasmic reticulum. The third mutation is a large genomic lesion of $85 \mathrm{~kb}$, affecting 29 genes (Seidl et al., 2008), including transcription factors and enzymes of the primary metabolism. Some of the genes lacking in 
RUT-C30 could be correlated with pronounced alterations in its phenotype, such as poor growth on a-linked oligosaccharides. This deletion of $85 \mathrm{~kb}$ is also present in NG14.

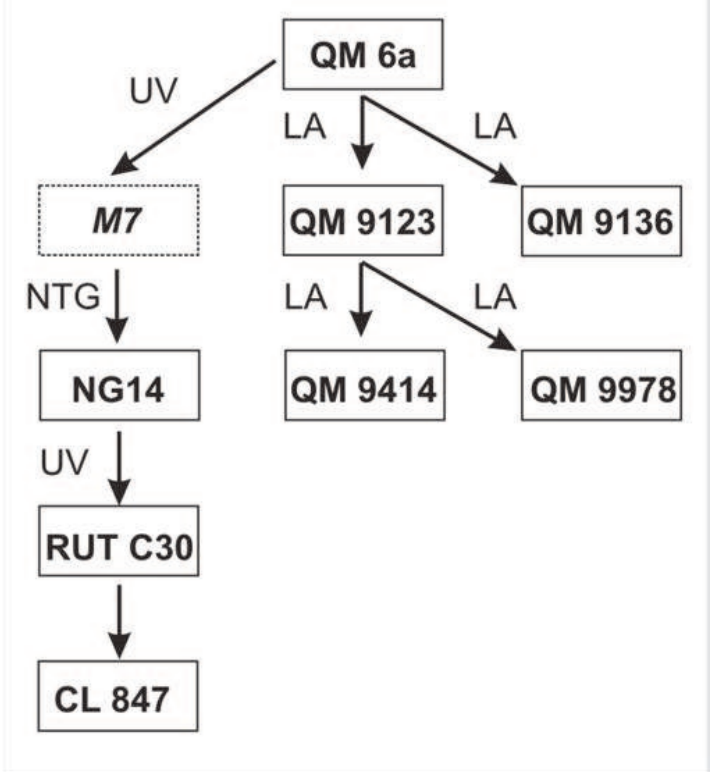

Fig. 3. Pedigree of important T. reesei strains derived from the original isolate QM6a by classical mutagenesis. The mutagens used are either irradiation by linear particle accelerators (LA), UV light (UV) or NTG. All the strains except CL487 are sequenced by the Joint Genome Institute. Strain M7 is indicated in italics as it is not available any more. QM9136 and QM9978 are deficient in cellulase production.

\subsection{Genome wide approaches to understand cellulase hyperproduction}

The T. reesei QM6a derived mutant series form a unique pedigree of strains in which each mutant shows an improved ability to produce cellulases compared to its parental strain. Besides these strains there are also mutants available with defects in cellulase expression (Fig. 3). From these mutagenesis programmes it is also evident that several mutations and not just one or two gene modifications are necessary to make a significantly improved cellulase producer strain. It can be expected that a large number of gene alterations are found in these strains affecting the protein synthesis and the secretion ability. The analysis of mutations in high-producing $T$. reesei strains would increase our understanding of the mechanisms underlying efficient cellulase production and their analysis might reveal new key players in cellulase expression. Since most of the improved producer strains (e.g. RUT C30) were subsequently also used in industrial strain improvement programs, the additional mutations found in these industrial hyperproducers could give even further leads on how to improve protein production. The knowledge of the gene alterations would allow targeted genetic engineering for improved production of cellulases and proteins in general. 
With the genome sequence of strain QM6a as a reference, it is now possible to use highthroughput methods such as massively parallel DNA sequencing or comparative genomic hybridization (CGH) to detect mutations in these strains. Using massive parallel sequencing numerous mutations were identified in the mutant line consisting of NG14 and RUT-C30 (Le Crom et al., 2009). This analysis revealed 223 single nucleotide variants (SNVs) and 15 small indels (insertions and deletions), and 18 larger deletions which led to the loss of more than $100 \mathrm{~kb}$ of genomic DNA in the cellulase overproducing strains. The SNVs resulted in mutations in more than 50 genes which are surprisingly found only in a small group of functions including nuclear transport, transcription, mRNA stability, protein secretion and vacuolar targeting. In both strains, NG14 and RUT-C30, a number of genes belonging to these functional categories are mutated. Interestingly, with the exception of CRE1, none of the transcriptional regulators of cellulase expression (XYR1, ACE1, ACE2 or HAP complex) or the proteinmethyltransferase LAE1 were affected in these strain lines by the different rounds of mutagenesis. These results highlight additional mechanisms which can be of importance for cellulase hyperproduction but they also underscore the complexity of the problem: it will be part of the future research to find out which mutations are detrimental, neutral or beneficial for cellulase production. In a recent study the analysis of genomic alterations was extended to QM9414 and QM9123 (Vitikainen et al., 2010) by array comparative genomic hybridization (aCGH), which allows the analysis of smaller genomes with oligonucleotide tiling arrays at a single nucleotide resolution on a single chip. Again, a large number of genomic alterations were detected in all four cellulase mutant strains. In strains QM9123 and QM9414 a total of 44 novel mutations including 4 translocation breakpoints were detected while in the RUT-C30 line additional 17 mutations to the ones detected by Le Crom et al. (2009) were found. Further, also a number of chromosomal translocation breakpoints were detected in RUT-C30. These results confirm earlier conclusion from electrophoretic karyotyping which indicated differences in the size of the RUT-C30 chromosomes when compared to QM9414, probably due to chromosomal rearrangements. Gene mapping by hybridization had also already pointed to additional rearrangements in the gene order between these strain lines (Carter et al., 1992; Mantyla et al., 1992). It is possible that these chromosomal rearrangements also play a role in cellulase regulation since wide domain regulation as found for LAE1 might be affected in such strains.

Based on the results from these genomic studies, new hypotheses about the mechanisms underlying cellulase and hemicellulase production and secretion in T. reesei were developed and novel areas for strain improvement such as nuclear transport, mRNA turnover and vacuolar protein trafficking will now be tested. Till now only two new deletions identified in RUT-C30 (the deletion of an $85 \mathrm{~kb}$ region and the deletion of a gene encoding a transcription factor) were tested for cellulase production by constructing knock-out strains, but both deletions did not affect cellulase production. It will be interesting for future research, to see if there is a synergism between the mutations and if some mutations might only become operative in the right genomic background.

\section{Advanced tool boxes for genetic engineering and strain breeding}

Results from genome-wide approaches including the $T$. reesei genome sequencing and annotation project, high-throughput sequencing of improved $T$. reesei strains and microarray analysis under cellulase inducing conditions, provided researchers with long lists of potential candidate genes for further investigations to better understand and further 
improve cellulase production. Although some of these genes encode proteins with wellcharacterized orthologues in other fungi and thus their general functions might be predictable, their relevance for cellulase production still needs to be evaluated. Further, many of the newly discovered genes are annotated as 'hypothetical proteins', which indicates that it is difficult to predict any function at all for these proteins. A key technique to assess gene functions and to alter the characteristics of fungal strains is the inactivation of genes by targeted deletion or knock-out. With such a technique, organisms are genetically engineered in such a way that a particular gene (target gene) is completely absent from the organism (it has been "knocked out" in the organism). To facilitate gene knockouts, individual cells are genetically transformed with a DNA construct, the gene deletion fragment. This construct consists of the promoter and terminator region of a selected gene, but the gene's coding region (encoding the protein) is replaced by a marker gene. When this gene deletion cassette is introduced into the organism by transformation, it is able to recombine with the target gene in the organism's genome. Recombination occurs between the promoter and terminator region of the gene deletion fragment and the target gene, resulting in its replacement by the marker in the genome.

The marker gene is also essential to discriminate between fungal cells which were transformed by the gene deletion fragment and those which did not incorporate the DNA. Marker genes can either confer antibiotic resistance (dominant marker) or complement an auxotrophy (auxotrophic marker) and thus enable selection of transformed cells. Auxotrophy is the inability of an organism to synthesize a particular organic compound required for its growth. Functional genetic studies on a large scale basis depend on the construction of well defined gene deletion strains with an efficient gene targeting system. So far the generation of gene deletion strains in filamentous fungi such as $T$. reesei was a time consuming process and the established working procedures were not suitable for carrying out gene deletions on a high-throughput basis. Therefore adequate molecular tool boxes were developed in the last years to overcome these bottlenecks to be able to perform such gene deletions on a large scale basis.

The first limiting step was the construction of the gene deletion fragment itself. Usually this fragment was assembled in a time consuming process based on different genetic engineering techniques including several rounds of DNA restriction digests, DNA ligations and transformations in E. coli followed by the verification of the construct before it could be used for fungal transformation and gene deletion. Different methods to facilitate the large scale production of deletion vector constructs were developed which now enable us to bypass traditional vector construction methods. One method to construct deletion fragments relies on the polymerase chain reaction (PCR) and assembles the three fragments simply by PCR bypassing ligation and restriction digests. Another method was successfully tested for N. crassa genome project (Colot et al., 2006). This method takes advantage of recombinational cloning in S. cerevisiae to rapidly create knockout cassettes (Fig. 4). The different fragments of the deletion construct are individually amplified by PCR with additional short, overlapping ends. The PCR fragments are then transformed into yeast cells and are there assembled to the complete gene deletion fragment by the endogenous recombination machinery via the overlapping ends of the PCR fragments. Once recombination has taken place, the DNA vector can be extracted from the yeast cells and the complete deletion construct can be amplified by PCR. A similar strategy was recently also developed for $T$. reesei (unpublished results). 


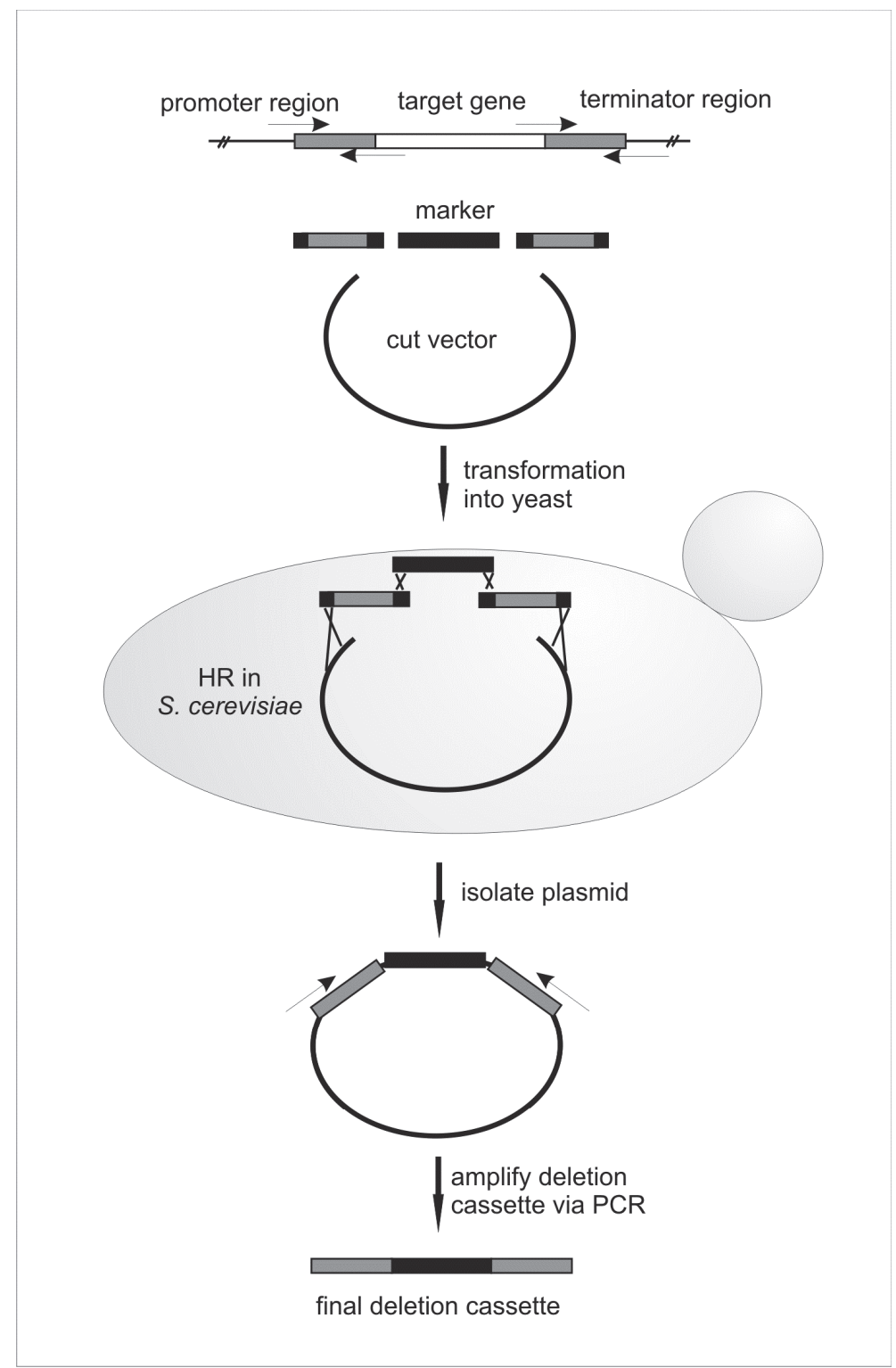

Fig. 4. High-throughput construction of gene deletion fragments by yeast recombinational cloning. Promoter and terminator regions (in grey) of the target gene are amplified from genomic DNA with homologous overlapping ends to the marker gene (white) and to the vector sequence. The flanking regions, the marker gene and the restricted vector are then introduced by cotransformation into $S$. cerevisiae where the deletion vector is assembled by homologous recombination. Subsequently, the deletion vector is extracted and the cassette amplified by PCR. 
Another major obstacle for functional genetic studies is the general low frequency of homologous recombination (HR) of filamentous fungi in comparison to the yeast $S$. cerevisiae. This HR frequency is typically ca. $10 \%$ in T. reesei. This means that only in one of ten fungal cells that contain the gene deletion fragment the target gene has been deleted while in the other nine the DNA fragment is inserted somewhere else in the genome (= ectopic integration). HR depends on the genomic locus, the genetic marker and the size of the flanking regions. As a consequence of the predominant ectopic insertion of the deletion fragment during genetic transformations, numerous transformants have to be screened to detect the desired ones where a HR between the target gene and the deletion fragment had occurred. Integration of DNA fragments in the genome requires the action of double strand repair mechanisms and is mediated by two main pathways (Fig. 5A), the homologous recombination pathway (HR) and the nonhomologous end joining pathway (NHEJ). The NHEJ pathway seems to be the dominant mode of DNA integration in most fungi including $T$. reesei leading to a ligation of strands without sequence similarity. To improve HR frequencies it is necessary to eliminate this ectopic (random) integration of the deletion cassette or to improve HR frequencies. Impairment of NHEJ seems to be the preferred solution and is usually achieved by inactivation of key components of the NHEJ pathway such as the DNA binding KU70 or 80 proteins (Krappmann, 2007). T. reesei strains in which the corresponding $t k u 70$ gene was deleted show improved gene targeting $(90-100 \%)$ and allow gene knockout studies on a high throughput basis using $1 \mathrm{~kb}$ homologous flanking regions (Guangtao et al., 2009). Although this system represents a considerable breakthrough for the study of gene functions in filamentous fungi, studies on the potential side effect resulting from an impaired NHEJ pathway on genome stability and integrity are not available yet. Potentially deleterious effects of this $t k u 70$ deletion can be minimized by reintroduction of the $t k u 70$ gene via transformation or via sexual recombination in sexually propagating fungi, or by only transiently inactivation of the $t k u 70$ gene.

In T. reesei, DNA mediated transformation relies on a small number of dominant and auxotrophic markers, which generally limit the number of genetic manipulations. In addition, the presence of dominant markers is often undesired in industrial strains and might be an obstacle in product approval processes. As a solution for all of these problems recyclable markers were developed. Different systems are available that are suitable for removing the marker gene after each transformation step and allowing the reapplication of the same marker in the next round of transformation. The "blaster cassette" is one option to facilitate the removal of the marker (Fig. 5B). Here the marker gene is located between two direct repeats of about $500 \mathrm{bp}$, which favours excision of the marker by HR between these repeats. This blaster cassette can then be reused for multiple rounds of gene deletions as was already exemplified in $T$. reesei, where we consecutively deleted two hexokinase genes with a blaster cassette (Hartl and Seiboth, 2005). The blaster approach relies on naturally occurring recombination between the two direct repeats flanking the marker gene, which occurs at a relatively low frequency (ca. 1: 104-106) and relies on the use of a bidirectional marker (see below).

Other recombination systems introduce a specific recombinase (Fig. 5C), which detects short stretches of DNA with a specific sequence and recombines these sites, thereby removing the DNA between the sites. The advantage of this approach is a relatively high recombination frequency, but it requires an additional gene - encoding the recombinase - which has to be regulated in such a way that the marker gene is not removed during the initial fungal transformation but only at a later stage when the removal of the marker gene is desired. 
Examples for such systems are the Cre/loxP system from $E$. coli bacteriophage P1 or the $S$. cerevisiae FLP/FRT system. Both depend on a site-specific recombination mediated by the Cre or FLP recombinase and recognition sites that serve as specific recombinase binding sites (loxP or FRT).

\section{A}

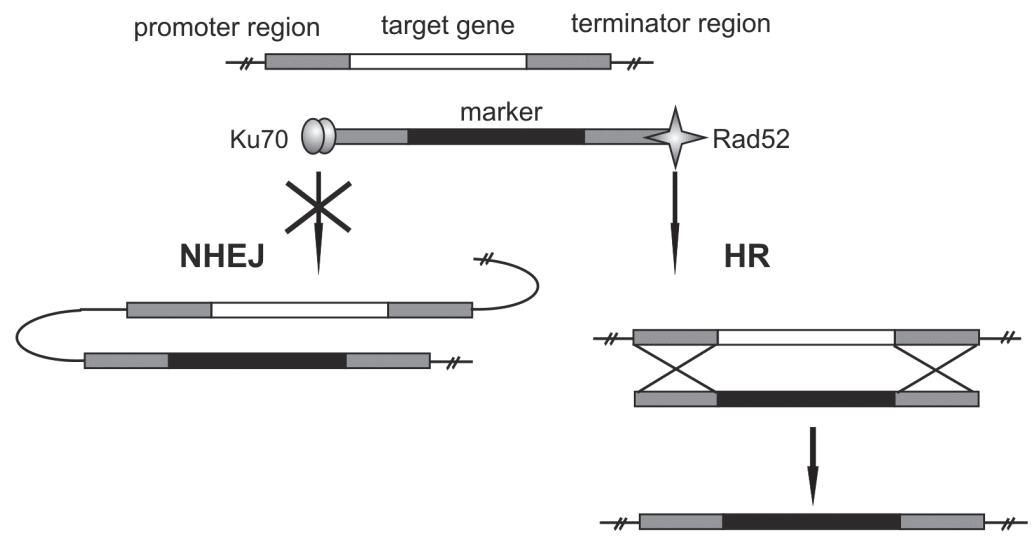

B

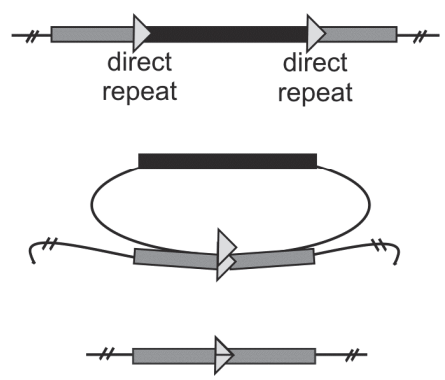

C
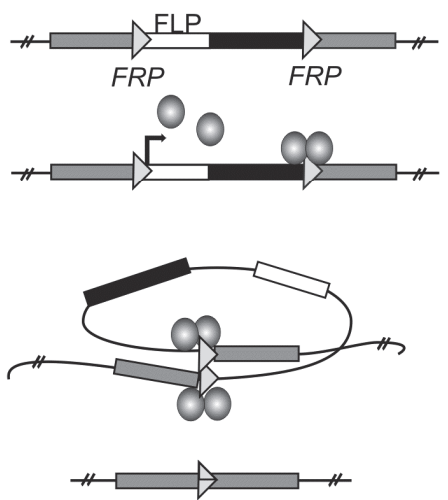

Fig. 5. Homologous DNA integration and different marker removal systems. (A) The HR and NHEJ pathway mediate the integration of DNA into the genome. Inactivation of Ku70 or Ku80 genes or the amplification of Rad52 improve HR frequencies. Marker recycling by a blaster cassette approach (B) or by a FLP/FRT recombination system (C). Blaster cassettes are composed of a marker cassette flanked by two direct repeats are responsible for the excision of the blaster cassette by homologous recombination after transformation. In the FLP mediated system the FLP recombinase is introduced with the marker gene and mediates the recombination between two FRT sequences (Kopke et al., 2010). 
Bidirectional genetic markers, which can be used to select for the absence and presence of the marker, are essential for the application of blaster cassettes but are also advantageous in the recombinase system instead of the normal (unidirectional) markers. Bidirectional selection is accomplished by first selecting for the presence of the marker during the fungal transformation (=positive selection). For example, in the case of a dominant positive selection, the presence of the marker gene results in the resistance of the transformant to a certain antibiotic. Afterwards the loss/absence of the marker is tested (= negative selection). In case the marker gene is still present, the transformant will be sensitive to a certain toxic substance. In the absence of the marker this substance cannot be metabolized and is therefore not toxic anymore. The $T$. reesei pyr4 gene (encoding orotidine 5'-phosphate carboxylase) is an example for a bidirectional marker. The pyr4 gene confers uridine/uracil prototrophy, it is therefore possible to select for the presence or the absence of the marker. Transformants where pyr4 has integrated into the genomic DNA are selected via pyr4 function. Such transformants are able to grow on medium without uridine supplementation. These transformants, however, are sensitive to 5-FOA (5-fluorotic acid) and thus removal of the pyr4 marker by one of the above described methods results in strains which are insensitive to 5-FOA. Similar bidirectional marker cassettes were constructed by fusing a dominant positive marker with a negative marker, e.g. a phleomycin resistance gene was fused in-frame with the herpes simplex virus type 1 thymidine kinase gene. This gene fusion confers phleomycin resistance for dominant positive selection and ganciclovir sensitivity for negative selection (Krappmann et al., 2005).

Although considerable progress has been made in the last decades to understand cellulase production in $T$. reesei by making use of gene deletion strains and other molecular biological tools, the cellulase secretion levels of strains such as RUT C30 or CL487 that were derived from random mutagenesis programs could not be reached. Thus, as described in section 4.2, the interest in the complete set of mutations of these strains was renewed in the past few years by the availability of genome-wide approaches. The results yielded long lists with the total numbers of mutations and most of them have not been functionally analyzed yet. While some of them probably are the cause for cellulase hyperproduction, others are certainly deleterious and it is desirable to repair them in order to improve the fitness of the strain and thus possibly increase cellulase production. Due to the limitations of genetic engineering outlined above, another way to speed up the analysis of these mutations would be the meiotic recombination through sexual crossing. Interestingly, industrially applied filamentous fungal species have so far been considered to be largely asexual. This was also the case for $T$. reesei for more than 50 years, but analysis of the genome sequence of $T$. reesei QM6a provided evidence for its sexual cycle and showed that this is a so-called heterothallic species, which needs another strain of the opposite mating type for sexual propagation. Genome analysis of QM6a revealed an intact mating type locus and using appropriate $H$. jecorina wild-type isolates with the correct opposite mating type enabled us recently to successfully cross $T$. reesei QM6a for the first time under laboratory conditions (Seidl et al., 2009). In other fungi, for example the model organisms N. crassa and A. nidulans, sexual crossing is, a commonly used technique to combine fungal strain properties. This approach enables the isolation and characterization of auxotrophic mutants and is the reason, why transformation strategies that involve the conversion of auxotrophic mutants to prototrophy are so far only poorly developed in $T$. reesei. Sexual propagation would also be important for repairing detrimental mutations in $T$. reesei production strain lines. Another important application would be the back-crossing of deleted genes, for example the $t k u 70$ gene that 
aids in generating gene deletion strains but in the long term might be important for chromosome stability of the fungus. Although successful sexual crossing of T. reesei QM6a and notably also of other cellulase hyperproducing mutants including RUT-C30, has been a milestone for strain development in T. reesei, several drawbacks still need to be overcome. So far $T$. reesei strains can only be crossed with $H$. jecorina wild-type strains and genetic analysis indicated that the T. reesei QM6a strain line has a genetic defect and is not able to develop female fruiting bodies. Therefore, QM6a can only serve as the male mating partner during sexual propagation. Further research will be necessary to elucidate the reasons for this deficiency and to fully establish a system similar to the model fungi $N$. crassa or A. nidulans.

\section{Conclusion}

The analysis of the complete genome sequence of $T$. reesei has resulted in the surprising finding that this industrial (hemi)cellulase producer has only a relatively small set of enzymes involved in plant cell wall degradation. This indicates that the efficiency of the enzyme mixtures of $T$. reesei can be further improved by the addition of other cellulases and non-enzymatic proteins. However, even with its apparently limited set of cellulolytic enzymes $T$. reesei gained significant industrial importance over the past decades due to its still yet unmatched enzyme production capacities. The large numbers of mutations detected in different production strain lines by recent advances in genome-wide analysis approaches underscore our limited understanding of the regulatory processes underlying cellulase production and suggest yet unexploited potentials to further improve enzyme production and strain breeding including nuclear transport, transcription, mRNA stability, protein secretion and vacuolar targeting. The relevance of all these alterations can in the next years be tested by using the recently developed toolboxes that enable fungal strain improvement on a high-throughput basis.

\section{Acknowledgment}

The FWF (Austrian Science Fund) supported BS by grant P19421 and VS by P20559 and a Hertha-Firnberg grant (T390).

\section{References}

Adney, W.S.; Chou, Y.C.; Decker, S.R.; Ding, S.Y.; Baker, J.O.; Kunkel, G.; Vinzant, T.B. \& Himmel, M.E. (2003). Heterologous expression of Trichoderma reesei 1,4-beta-Dglucan cellobiohydrolase (Cel 7A). In, Applications of Enzymes to Lignocellulosics Amer Chemical Soc., ISBN pp. 403-437, Washington, USA

Aro, N.; Pakula, T. \& Penttilä, M. (2005). Transcriptional regulation of plant cell wall degradation by filamentous fungi. FEMS Microbiology Reviews, Vol.29, No. 4, pp. 719-739, ISSN 0168-6445

Barr, B.K.; Hsieh, Y.L.; Ganem, B. \& Wilson, D.B. (1996). Identification of two functionally different classes of exocellulases. Biochemistry, Vol.35, No. 2, pp. 586-592, ISSN 0006-2960

Bayer, E.A.; Chanzy, H.; Lamed, R. \& Shoham, Y. (1998). Cellulose, cellulases and cellulosomes. Current Opinion in Structural Biology, Vol.8, No. 5, pp. 548-557, ISSN 0959-440X 
Beckham, G.T.; Bomble, Y.J.; Matthews, J.F.; Taylor, C.B.; Resch, M.G.; Yarbrough, J.M.; Decker, S.R.; Bu, L.; Zhao, X.; McCabe, C.; Wohlert, J.; Bergenstrahle, M.; Brady, J.W.; Adney, W.S.; Himmel, M.E. \& Crowley, M.F. (2010). The O-glycosylated linker from the Trichoderma reesei Family 7 cellulase is a flexible, disordered protein. Biophysical journal, Vol.99, No. 11, pp. 3773-3781, ISSN 1542-0086

Beguin, P. \& Aubert, J.P. (1994). The biological degradation of cellulose. FEMS Microbiology Reviews, Vol.13, No. 1, pp. 25-58, ISSN 0168-6445

Bouws, H.; Wattenberg, A. \& Zorn, H. (2008). Fungal secretomes--nature's toolbox for white biotechnology. Applied Microbiology and Biotechnology, Vol.80, No. 3, pp. 381-388, ISSN 1432-0614

Cantarel, B.L.; Coutinho, P.M.; Rancurel, C.; Bernard, T.; Lombard, V. \& Henrissat, B. (2009). The Carbohydrate-Active EnZymes database (CAZy): an expert resource for Glycogenomics. Nucleic Acids Research, Vol.37, No. Database issue, pp. D233-238, ISSN 1362-4962

Carle-Urioste, J.C.; Escobar-Vera, J.; El-Gogary, S.; Henrique-Silva, F.; Torigoi, E.; Crivellaro, O.; Herrera-Estrella, A. \& El-Dorry, H. (1997). Cellulase induction in Trichoderma reesei by cellulose requires its own basal expression. Journal of Biological Chemistry, Vol.272, No. 15, pp. 10169-10174, ISSN 0021-9258

Carroll, A. \& Somerville, C. (2009). Cellulosic biofuels. Annual Revies in Plant Biology, Vol.60, No., pp. 165-182, ISSN 1545-2123

Carter, G.L.; Allison, D.; Rey, M.W. \& Dunn-Coleman, N.S. (1992). Chromosomal and genetic analysis of the electrophoretic karyotype of Trichoderma reesei: mapping of the cellulase and xylanase genes. Molecular microbiology, Vol.6, No. 15, pp. 21672174, ISSN 0950-382X

Cherry, J.R. \& Fidantsef, A.L. (2003). Directed evolution of industrial enzymes: an update. Current Opinion in Biotechnology, Vol.14, No. 4, pp. 438-443, ISSN 0958- 1669

Colot, H.V.; Park, G.; Turner, G.E.; Ringelberg, C.; Crew, C.M.; Litvinkova, L.; Weiss, R.L.; Borkovich, K.A. \& Dunlap, J.C. (2006). A high-throughput gene knockout procedure for Neurospora reveals functions for multiple transcription factors. Proceedings of the National Academy of Science U S A, Vol.103, No. 27, pp. 1035210357, ISSN 0027-8424

Divne, C.; Stahlberg, J.; Reinikainen, T.; Ruohonen, L.; Pettersson, G.; Knowles, J.K.; Teeri, T.T. \& Jones, T.A. (1994). The three-dimensional crystal structure of the catalytic core of cellobiohydrolase I from Trichoderma reesei. Science, Vol.265, No. 5171, pp. 524-528., ISSN 0036-8075

Druzhinina, I.S.; Komon-Zelazowska, M.; Atanasova, L.; Seidl, V. \& Kubicek, C.P. (2010). Evolution and ecophysiology of the industrial producer Hypocrea jecorina (Anamorph Trichoderma reesei) and a new sympatric agamospecies related to it. PLoS One, Vol.5, No. 2, pp. e9191, ISSN 1932-6203

Flipphi, M.; van de Vondervoort, P.J.; Ruijter, G.J.; Visser, J.; Arst, H.N., Jr. \& Felenbok, B. (2003). Onset of carbon catabolite repression in Aspergillus nidulans. Parallel involvement of hexokinase and glucokinase in sugar signaling. The Journal of Biological Chemistry, Vol.278, No. 14, pp. 11849-11857, ISSN 0021-9258

Foreman, P.K.; Brown, D.; Dankmeyer, L.; Dean, R.; Diener, S.; Dunn-Coleman, N.S.; Goedegebuur, F.; Houfek, T.D.; England, G.J.; Kelley, A.S.; Meerman, H.J.; Mitchell, T.; Mitchinson, C.; Olivares, H.A.; Teunissen, P.J.; Yao, J. \& Ward, M. (2003). 
Transcriptional regulation of biomass-degrading enzymes in the filamentous fungus Trichoderma reesei. The Journal of Biological Chemistry Vol.278, No. 34, pp. 31988-31997, ISSN 0021-9258

Geysens, S.; Pakula, T.; Uusitalo, J.; Dewerte, I.; Penttilä, M. \& Contreras, R. (2005). Cloning and characterization of the glucosidase II alpha subunit gene of Trichoderma reesei: a frameshift mutation results in the aberrant glycosylation profile of the hypercellulolytic strain Rut-C30. Applied and Environmental Microbiology, Vol.71, No. 6, pp. 2910-2924, ISSN 0099- 2240

Gritzali, M. \& Brown, R.D.J. (1979). The cellulase system of Trichoderma: relationship betweeen purified extracellular enzymes from induced or cellulose-grown cells. Advances in Chemistry Series Vol.181, No., pp. 237-260, ISSN 0065-2393

Guangtao, Z.; Hartl, L.; Schuster, A.; Polak, S.; Schmoll, M.; Wang, T.; Seidl, V. \& Seiboth, B. (2009). Gene targeting in a nonhomologous end joining deficient Hypocrea jecorina. Journal of Biotechnology, Vol.139, No. 2, pp. 146-151, ISSN 0168-1656

Harman, G.E. \& Kubicek, C.P. (1998). Trichoderma and Gliocladium. Enzymes, biological control and commercial applications, 2, Taylor \& Francis Ltd, ISBN 0748408061, London, Great Britain

Harris, P.V.; Welner, D.; McFarland, K.C.; Re, E.; Navarro Poulsen, J.C.; Brown, K.; Salbo, R.; Ding, H.; Vlasenko, E.; Merino, S.; Xu, F.; Cherry, J.; Larsen, S. \& Lo Leggio, L. (2010). Stimulation of lignocellulosic biomass hydrolysis by proteins of glycoside hydrolase family 61: structure and function of a large, enigmatic family. Biochemistry, Vol.49, No. 15, pp. 3305-3316, ISSN 1520-4995

Hartl, L. \& Seiboth, B. (2005). Sequential gene deletions in Hypocrea jecorina using a single blaster cassette. Current Genetics, Vol.48, No. 3, pp. 204-211, ISSN 0172-8083

Himmel, M.E.; Ding, S.Y.; Johnson, D.K.; Adney, W.S.; Nimlos, M.R.; Brady, J.W. \& Foust, T.D. (2007). Biomass recalcitrance: engineering plants and enzymes for biofuels production. Science, Vol.315, No. 5813, pp. 804-807, ISSN 1095-9203

Igarashi, K.; Koivula, A.; Wada, M.; Kimura, S.; Penttilä, M. \& Samejima, M. (2009). High speed atomic force microscopy visualizes processive movement of Trichoderma reesei cellobiohydrolase I on crystalline cellulose. The Journal of Biological Chemistry, Vol.284, No. 52, pp. 36186-36190, ISSN 1083-351X

Ilmen, M.; Saloheimo, A.; Onnela, M.L. \& Penttilä, M.E. (1997). Regulation of cellulase gene expression in the filamentous fungus Trichoderma reesei. Applied and Environmental Microbiology, Vol.63, No. 4, pp. 1298-1306., ISSN 0099- 2240

Ilmen, M.; Thrane, C. \& Penttilä, M. (1996). The glucose repressor gene cre1 of Trichoderma: isolation and expression of a full-length and a truncated mutant form. Molecular and General Genetics, Vol.251, No. 4, pp. 451-460, ISSN 0026-8925

Jalak, J. \& Valjamae, P. (2010). Mechanism of initial rapid rate retardation in cellobiohydrolase catalyzed cellulose hydrolysis. Biotechnology and Bioengineering, Vol.106, No. 6, pp. 871-883, ISSN 1097-0290

Jeoh, T.; Michener, W.; Himmel, M.E.; Decker, S.R. \& Adney, W.S. (2008). Implications of cellobiohydrolase glycosylation for use in biomass conversion. Biotechnology for Biofuels, Vol.1, No. 1, pp. 10, ISSN 1754-6834

Karkehabadi, S.; Hansson, H.; Kim, S.; Piens, K.; Mitchinson, C. \& Sandgren, M. (2008). The first structure of a glycoside hydrolase family 61 member, Cel61B from Hypocrea 
jecorina, at 1.6 A resolution. Journal of Molecular Biology, Vol.383, No. 1, pp. 144-154, ISSN 1089-8638

Keller, N.P.; Turner, G. \& Bennett, J.W. (2005). Fungal secondary metabolism - from biochemistry to genomics. Nature Reviews in Microbiology, Vol.3, No. 12, pp. 937947, ISSN 1740-1526

Kopke, K.; Hoff, B. \& Kuck, U. (2010). Application of the Saccharomyces cerevisiae FLP/FRT recombination system in filamentous fungi for marker recycling and construction of knockout strains devoid of heterologous genes. Applied and Environmental Microbiology, Vol.76, No. 14, pp. 4664-4674, ISSN 1098-5336

Krappmann, S. (2007). Gene targeting in filamentous fungi: the benefits of impaired repair. Fungal Biology Reviews, Vol.21, No. 1, pp. 25-29, ISSN 1749-4613

Krappmann, S.; Bayram, O. \& Braus, G.H. (2005). Deletion and allelic exchange of the Aspergillus fumigatus veA locus via a novel recyclable marker module. Eukaryotic Cell, Vol.4, No. 7, pp. 1298-1307, ISSN 1535-9778

Kubicek, C.P.; Mikus, M.; Schuster, A.; Schmoll, M. \& Seiboth, B. (2009). Metabolic engineering strategies for the improvement of cellulase production by Hypocrea jecorina. Biotechnol Biofuels, Vol.2, No., pp. 19, ISSN 1754-6834

Kubicek, C.P.; Seidl, V.; Zeilinger, S.; Kredics, L.; Nevalainen, H.; Deshpande, N.; Monte, E.; Wiest, A.; McCluskey, K.; Henrissat, B.; Coutinho, P.M.; Casas, S.; Misra, M.; Schmoll, M.; Antal, Z.; Tisch, D.; Seiboth, B.; Shapiro, H.; Zhang, M.; Challacombe, J.; Salamov, A.; Lindquist, E.; Lucas, S.; Mukherjee, M.; Hermosa, R.; Horwitz, B.; von Döhren, H.; Herrera-Estrella, A.; Baker, S.; Kenerley, C.M. \& Grigoriev, I.V. (2011). Genome sequence comparison of three species of Trichoderma reveals the evolutionary changes from saprophytic to mycoparasitic lifestyle. Genome Biology, in press. ISSN 1465-6906

Kumar, R.; Singh, S. \& Singh, O.V. (2008). Bioconversion of lignocellulosic biomass: biochemical and molecular perspectives. Journal of Indian Microbiology and Biotechnology, Vol.35, No. 5, pp. 377-391, ISSN 1367-5435

Lantz, S.E.; Goedegebuur, F.; Hommes, R.; Kaper, T.; Kelemen, B.R.; Mitchinson, C.; Wallace, L.; Stahlberg, J. \& Larenas, E.A. (2010). Hypocrea jecorina CEL6A protein engineering. Biotechnology for Biofuels, Vol.3, No., pp. 20, ISSN 1754-6834

Le Crom, S.; Schackwitz, W.; Pennacchio, L.; Magnuson, J.K.; Culley, D.E.; Collett, J.R.; Martin, J.; Druzhinina, I.S.; Mathis, H.; Monot, F.; Seiboth, B.; Cherry, B.; Rey, M.; Berka, R.; Kubicek, C.P.; Baker, S.E. \& Margeot, A. (2009). Tracking the roots of cellulase hyperproduction by the fungus Trichoderma reesei using massively parallel DNA sequencing. Proceedings of the National Academy of Science U S A, Vol.106, No. 38, pp. 16151-16156, ISSN 1091-6490

Li, X.L.; Spanikova, S.; de Vries, R.P. \& Biely, P. (2007). Identification of genes encoding microbial glucuronoyl esterases. FEBS Letters, Vol.581, No. 21, pp. 4029-4035, ISSN 0014-5793

Liu, Y.S.; Baker, J.O.; Zeng, Y.; Himmel, M.E.; Haas, T. \& Ding, S.Y. (2011). Cellobiohydrolase hydrolyzes crystalline cellulose on hydrophobic faces. The Journal of Biological Chemistry, No., ISSN 1083-351X

Mach-Aigner, A.R.; Pucher, M.E.; Steiger, M.G.; Bauer, G.E.; Preis, S.J. \& Mach, R.L. (2008). Transcriptional regulation of $x y r 1$, encoding the main regulator of the xylanolytic 
and cellulolytic enzyme system in Hypocrea jecorina. Applied and Environmental Microbiology, Vol.74, No. 21, pp. 6554-6562, ISSN 1098-5336

Mach, R.L.; Strauss, J.; Zeilinger, S.; Schindler, M. \& Kubicek, C.P. (1996). Carbon catabolite repression of xylanase I (xyn1) gene expression in Trichoderma reesei. Molecular Microbiology, Vol.21, No. 6, pp. 1273-1281., ISSN 0950-382X

Mantyla, A.L.; Rossi, K.H.; Vanhanen, S.A.; Penttilä, M.E.; Suominen, P.L. \& Nevalainen, K.M. (1992). Electrophoretic karyotyping of wild-type and mutant Trichoderma longibrachiatum (reesei) strains. Current Genetics, Vol.21, No. 6, pp. 471-477, ISSN 0172-8083

Martens-Uzunova, E.S. \& Schaap, P.J. (2009). Assessment of the pectin degrading enzyme network of Aspergillus niger by functional genomics. Fungal Genetics and Biology, Vol.46 Suppl 1, No., pp. S170-S179, ISSN 1096-0937

Martinez, D.; Berka, R.M.; Henrissat, B.; Saloheimo, M.; Arvas, M.; Baker, S.E.; Chapman, J.; Chertkov, O.; Coutinho, P.M.; Cullen, D.; Danchin, E.G.; Grigoriev, I.V.; Harris, P.; Jackson, M.; Kubicek, C.P.; Han, C.S.; Ho, I.; Larrondo, L.F.; de Leon, A.L.; Magnuson, J.K.; Merino, S.; Misra, M.; Nelson, B.; Putnam, N.; Robbertse, B.; Salamov, A.A.; Schmoll, M.; Terry, A.; Thayer, N.; Westerholm-Parvinen, A.; Schoch, C.L.; Yao, J.; Barabote, R.; Nelson, M.A.; Detter, C.; Bruce, D.; Kuske, C.R.; Xie, G.; Richardson, P.; Rokhsar, D.S.; Lucas, S.M.; Rubin, E.M.; Dunn-Coleman, N.; Ward, M. \& Brettin, T.S. (2008). Genome sequencing and analysis of the biomassdegrading fungus Trichoderma reesei (syn. Hypocrea jecorina). Nature Biotechnology, Vol.26, No. 5, pp. 553-560, ISSN 1546-1696

Merino, S.T. \& Cherry, J. (2007). Progress and challenges in enzyme development for biomass utilization. Advances in Biochemistry andEnginering/Biotechnology, Vol.108, No., pp. 95-120, ISSN 0724-6145

Montenecourt, B.S. \& Eveleigh, D.E. (1977). Preparation of mutants of Trichoderma reesei with enhanced cellulase production. Applied and Environmental Microbiology, Vol.34, No. 6, pp. 777-782, ISSN 0099-2240

Montenecourt, B.S. \& Eveleigh, D.E. (1979). Selective Screening Methods for the Isolation of High Yielding Cellulase Mutants of Trichoderma reesei, In, Hydrolysis of Cellulose: Mechanisms of Enzymatic and Acid Catalysis, Advances in Chemistry. American Chemical Society, ISBN pp. 289-301

Nakari-Setälä, T.; Paloheimo, M.; Kallio, J.; Vehmaanperä, J.; Penttilä, M. \& Saloheimo, M. (2009). Genetic modification of carbon catabolite repression in Trichoderma reesei for improved protein production. Applied and Environmental Microbiology, Vol.75, No. 14, pp. 4853-4860, ISSN 1098-5336

Nakari-Setälä, T. \& Penttilä, M. (1995). Production of Trichoderma reesei cellulases on glucosecontaining media. Applied and Environmental Microbiology, Vol.61, No. 10, pp. 36503655, ISSN 0099-2240

Nummi, M.; Niku-Paavola, M.L.; Lappalainen, A.; Enari, T.M. \& Raunio, V. (1983). Cellobiohydrolase from Trichoderma reesei. Biochemical Journal, Vol.215, No. 3, pp. 677-683, ISSN 0264-6021

Pakula, T.M.; Laxell, M.; Huuskonen, A.; Uusitalo, J.; Saloheimo, M. \& Penttilä, M. (2003). The effects of drugs inhibiting protein secretion in the filamentous fungus Trichoderma reesei. Evidence for down-regulation of genes that encode secreted 
proteins in the stressed cells. The Journal of Biological Chemistry, Vol.278, No. 45, pp. 45011-45020, ISSN 0021-9258

Palmer, J.M. \& Keller, N.P. (2010). Secondary metabolism in fungi: does chromosomal location matter? Current Opinion in Microbiology, Vol.13, No. 4, pp. 431-436, ISSN 1879-0364

Portnoy, T.; Margeot, A.; Seidl-Seiboth, V.; Le Crom, S.; Ben Chaabane, F.; Linke, R.; Seiboth, B. \& Kubicek, C.P. (2011). Differential regulation of the cellulase transcription factors XYR1, ACE2, and ACE1 in Trichoderma reesei strains producing high and low levels of cellulase. Eukaryotic Cell, Vol.10, No. 2, pp. 262-271, ISSN 1535-9786

Reese, E.T. (1976). History of the cellulase program at the U.S. Natick Development Center. Biotechnology Bioengineering Symposium, Vol.6, No., pp. 9-20

Rouvinen, J.; Bergfors, T.; Teeri, T.; Knowles, J.K. \& Jones, T.A. (1990). Three-dimensional structure of cellobiohydrolase II from Trichoderma reesei. Science, Vol.249, No. 4967, pp. 380-386, ISSN 1095-9203

Saloheimo, M.; Paloheimo, M.; Hakola, S.; Pere, J.; Swanson, B.; Nyyssonen, E.; Bhatia, A.; Ward, M. \& Penttilä, M. (2002). Swollenin, a Trichoderma reesei protein with sequence similarity to the plant expansins, exhibits disruption activity on cellulosic materials. European Journal of Biochemistry, Vol.269, No. 17, pp. 4202-4211, ISSN 0014-2956

Schülein, M. (2000). Protein engineering of cellulases. Biochimica et Biophysica Acta, Vol.1543, No. 2, pp. 239-252, ISSN 0006-3002

Seiboth, B.; Hakola, S.; Mach, R.L.; Suominen, P.L. \& Kubicek, C.P. (1997). Role of four major cellulases in triggering of cellulase gene expression by cellulose in Trichoderma reesei. Journal of Bacteriology, Vol.179, No. 17, pp. 5318-5320.,

Seiboth, B.; Messner, R.; Gruber, F. \& Kubicek, C.P. (1992). Disruption of the Trichoderma reesei $c b h 2$ gene coding for cellobiohydrolase II leads to a delay in the triggering of cellulase formation by cellulose Journal of General Microbiology, Vol.138, No., pp. 1259-1264, ISSN 0022-1287

Seiboth, B.; Pakdaman, B.S.; Hartl, L. \& Kubicek, C.P. (2007). Lactose metabolism in filamentous fungi: how to deal with an unknown substrate. Fungal Biology Reviews, Vol.21, No., pp. 42-48, ISSN 1749-4613

Seidl, V.; Gamauf, C.; Druzhinina, I.S.; Seiboth, B.; Hartl, L. \& Kubicek, C.P. (2008). The Hypocrea jecorina (Trichoderma reesei) hypercellulolytic mutant RUT C30 lacks a 85 $\mathrm{kb}$ (29 gene-encoding) region of the wild-type genome. BMC Genomics, Vol.9, No., pp. 327, ISSN 1471-2164

Seidl, V.; Seibel, C.; Kubicek, C.P. \& Schmoll, M. (2009). Sexual development in the industrial workhorse Trichoderma reesei. Proceedings of the National Academy of Science U S A, Vol.106, No. 33, pp. 13909-13914, ISSN 1091-6490

Stals, I.; Sandra, K.; Devreese, B.; Van Beeumen, J. \& Claeyssens, M. (2004a). Factors influencing glycosylation of Trichoderma reesei cellulases. II: N-glycosylation of Cel7A core protein isolated from different strains. Glycobiology, Vol.14, No. 8, pp. 725-737, ISSN 0959-6658

Stals, I.; Sandra, K.; Geysens, S.; Contreras, R.; Van Beeumen, J. \& Claeyssens, M. (2004b). Factors influencing glycosylation of Trichoderma reesei cellulases. I: Postsecretorial changes of the O- and N-glycosylation pattern of Cel7A. Glycobiology, Vol.14, No. 8, pp. 713-724, ISSN 0959-6658 
Tomme, P.; Warren, R.A. \& Gilkes, N.R. (1995). Cellulose hydrolysis by bacteria and fungi. Advances in Microbial Physiology, Vol.37, No., pp. 1-81, ISSN 0065-2911

Vaaje-Kolstad, G.; Vasella, A.; Peter, M.G.; Netter, C.; Houston, D.R.; Westereng, B.; Synstad, B.; Eijsink, V.G. \& van Aalten, D.M. (2004). Interactions of a family 18 chitinase with the designed inhibitor HM508 and its degradation product, chitobiono-deltalactone. The Journal of Biological Chemistry, Vol.279, No. 5, pp. 3612-3619, ISSN 00219258

Vaaje-Kolstad, G.; Westereng, B.; Horn, S.J.; Liu, Z.; Zhai, H.; Sorlie, M. \& Eijsink, V.G. (2010). An oxidative enzyme boosting the enzymatic conversion of recalcitrant polysaccharides. Science, Vol.330, No. 6001, pp. 219-222, ISSN 1095-9203

Vaheri, M.; Leisola, M. \& Kaupinnen, V. (1979). Transglycosylation products of the cellulase system of Trichoderma reesei. Biotechnology Letters, Vol.1, No., pp. 41-46, ISSN 01415492.

Verbeke, J.; Coutinho, P.; Mathis, H.; Quenot, A.; Record, E.; Asther, M. \& Heiss-Blanquet, S. (2009). Transcriptional profiling of cellulase and expansin-related genes in a hypercellulolytic Trichoderma reesei. Biotechnology Letters, Vol.31, No. 9, pp. 13991405, ISSN 1573-6776

Vitikainen, M.; Arvas, M.; Pakula, T.; Oja, M.; Penttilä, M. \& Saloheimo, M. (2010). Array comparative genomic hybridization analysis of Trichoderma reesei strains with enhanced cellulase production properties. BMC Genomics, Vol.11, No., pp. 441, ISSN 1471-2164

Wilson, D.B. (2009). Cellulases and biofuels. Current Opinion in Biotechnology, Vol.20, No. 3, pp. 295-299, ISSN 1879-0429

Zhang, Y.H. \& Lynd, L.R. (2006). A functionally based model for hydrolysis of cellulose by fungal cellulase. Biotechnology and Bioengineering, Vol.94, No. 5, pp. 888-898, ISSN 0006-3592 


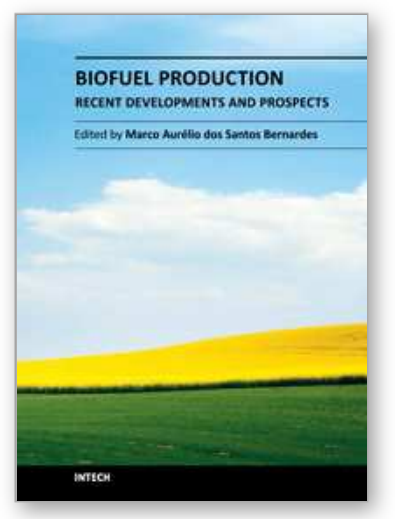

\section{Biofuel Production-Recent Developments and Prospects \\ Edited by Dr. Marco Aurelio Dos Santos Bernardes}

ISBN 978-953-307-478-8

Hard cover, 596 pages

Publisher InTech

Published online 15, September, 2011

Published in print edition September, 2011

This book aspires to be a comprehensive summary of current biofuels issues and thereby contribute to the understanding of this important topic. Readers will find themes including biofuels development efforts, their implications for the food industry, current and future biofuels crops, the successful Brazilian ethanol program, insights of the first, second, third and fourth biofuel generations, advanced biofuel production techniques, related waste treatment, emissions and environmental impacts, water consumption, produced allergens and toxins. Additionally, the biofuel policy discussion is expected to be continuing in the foreseeable future and the reading of the biofuels features dealt with in this book, are recommended for anyone interested in understanding this diverse and developing theme.

\section{How to reference}

In order to correctly reference this scholarly work, feel free to copy and paste the following:

Bernhard Seiboth, Christa Ivanova and Verena Seidl-Seiboth (2011). Trichoderma reesei: A Fungal Enzyme Producer for Cellulosic Biofuels, Biofuel Production-Recent Developments and Prospects, Dr. Marco Aurelio Dos Santos Bernardes (Ed.), ISBN: 978-953-307-478-8, InTech, Available from: http://www.intechopen.com/books/biofuel-production-recent-developments-and-prospects/trichoderma-reeseia-fungal-enzyme-producer-for-cellulosic-biofuels

\section{INTECH}

open science | open minds

\author{
InTech Europe \\ University Campus STeP Ri \\ Slavka Krautzeka 83/A \\ 51000 Rijeka, Croatia \\ Phone: +385 (51) 770447 \\ Fax: +385 (51) 686166 \\ www.intechopen.com
}

\author{
InTech China \\ Unit 405, Office Block, Hotel Equatorial Shanghai \\ No.65, Yan An Road (West), Shanghai, 200040, China \\ 中国上海市延安西路65号上海国际贵都大饭店办公楼405单元 \\ Phone: +86-21-62489820 \\ Fax: +86-21-62489821
}


(C) 2011 The Author(s). Licensee IntechOpen. This chapter is distributed under the terms of the Creative Commons Attribution-NonCommercialShareAlike-3.0 License, which permits use, distribution and reproduction for non-commercial purposes, provided the original is properly cited and derivative works building on this content are distributed under the same license. 